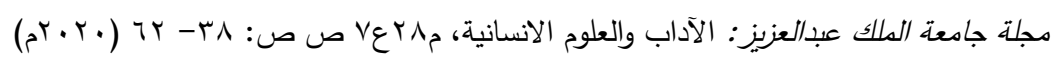

DOI:10.4197/Art.28-7.3

\title{
دور كلية التربية بجامعة حائل في تعزيز المسؤولية الاجتماعية عند الطالبات في ضوء رؤية · ب • ب للمملكة العربية السعودية
}

\section{د. هيفاء علي محمود طيفور}

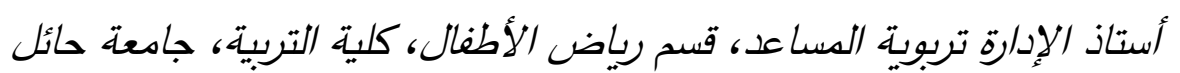

مستخلص. هدفت هذه الدراسة إلى التعرف على دور كلية التربية بجامعة حائل في تعزيز المسؤولية الاجتماعية

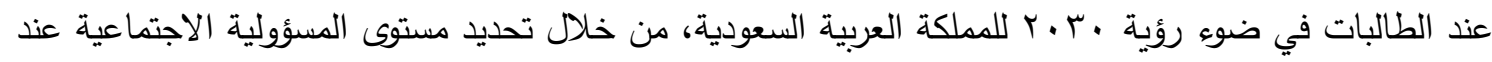
الطالبات، وتحديد الاختلاف في مستوى المسؤولية الاجتماعية وفقا لتأثير متغيرات الدراسة، والتعرف على أهم معوقات تعزيز المسؤولية الاجتماعية عند الطالبات، وتحديد المقترحات التي تسهم في تعزيز المسؤولية الاجتماعية لديهن، ولتحقيق أهداف الدراسة، استخدمت الباحثة المنهج الوصفي التحليلي، فقد تم تصميم استبيان لجمع البيانات،

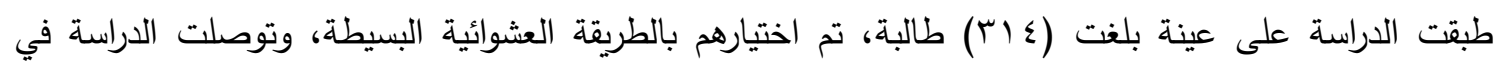

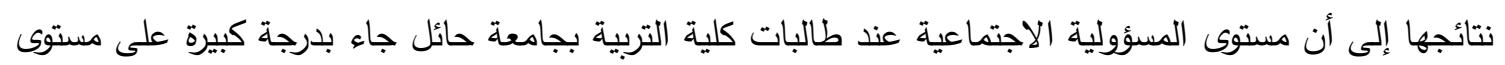
الأداة الكلية وعلى جميع المجالات، وكثفت أيضاً وجود فروق داله احصائياً في مستوى المسؤولية الاجتماعية تعزى لمتغير السنة الدراسية، وعدم وجود فروق داله احصائياً تعزى لمتغير التقدير ، وكشفت النتائج أيضاً أن أهم معوقات تعزيز المسؤولية الاجتماعية عند الطالبات عدم وجود قنوات ووسائل اتصال واضحة ومحددة بين الكلية والمجتمع الخارجي، وأن أكثر المقترحات التي تسهم في تعزيز المسؤولية الاجتماعية، إيجاد آليات لتشجيع وتحفيز

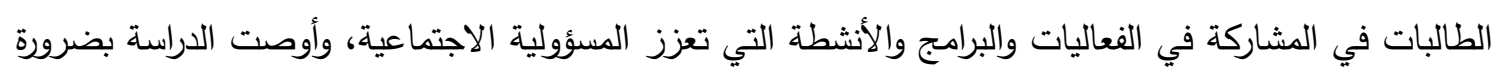
العمل على ايجاد البرامج التعليمية والإرشادية المناسبة التي تعمل على رفع مستوى المسؤولية الاجتماعية لدى الطالبات.

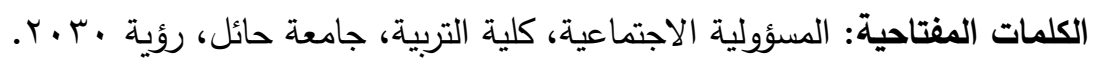

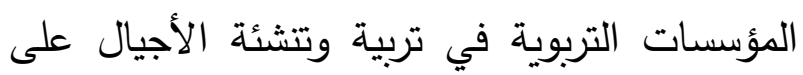
العقيدة الإسلامية وتتمية العادات والتقاليد والأعراف

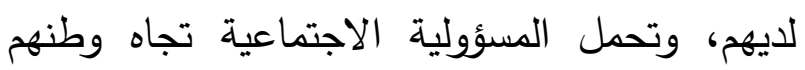
ومجتمعهم وبيئتهم.

\section{خلفية البحث}

يؤدي التعليم دورأ مهما في تقدم المجتمعات وتطورها، وغرس قيم ومبادئ الولاء والانتماء للوطن

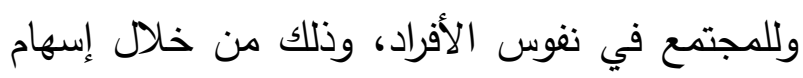


محلياً وعالمياً من خلال برامج طموحة تحقق ذلك،

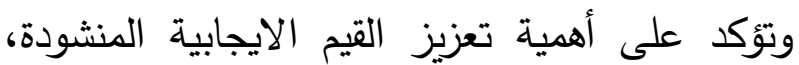
والمسؤولية الاجتماعية في شخصيات الطلاب. .(https://vision2030.gov.sa) وتعد الجامعات من المؤسسات التربوية التي تقوم بدور مهم في إعداد الأفراد، واكسابهم المعارف والمعلومات والعادات والمهارات والسلوكيات الصحيحة، من خلال البرامج والخطط التي تتفذها، والتي تساهم في بناء الثخصية المتكاملة من جميع الجوانب، وبث روح المسؤولية لديهم والاعتماد على النفس، وتحمل مسؤوليات الحياة، واثارة الدافعية لديهم للإنجاز والعمل، كما تسعى الجامعات إلى ولى

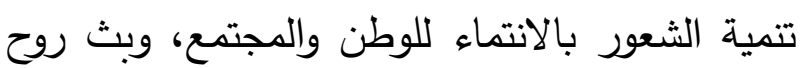

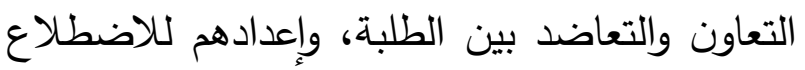
بمسؤولياتهم حيال التتمية الاقتصادية والاجتماعية، وصقل تفكيرهم ليعرفوا حقوقهم وواجباتهم (العبيد، .$(r \cdot 17$

إن أحد الجوانب المهمة للمسؤولية الاجتماعية للجامعات هو تتمية مواهب الطلاب؛ ليكونوا مواطنين منتجين ومسؤولين ومورداً كبيراً لمساعدة هواها المجتمعات، في عصر تتزايد فيه النزاعات السياسية، يتعين على الجامعات أن تغرس في طلابها تفهم

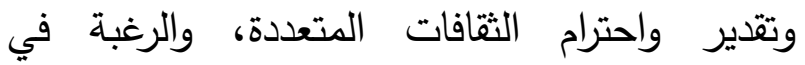
مساعدة الأقل حظاً، ومعالجة التحديات والمستجدات المختلفة. وتثمل برامج تعزيز المسؤولية الاجتماعية كلاً من الأنشطة الصفية واللاصفية، وتشجيع مبادئ
ولقد جاء إعلان رؤية السعودية (•r.r) للمملكة العربية السعودية مواكباً لرسالة التعليم وداعما لمسيرتها، لبناء جيل قادر على تحمل المسؤولية واتخاذ القرارات، وانطلاقاً من هذه الرسالة جاءت الرؤية لتوفير فرص التعليم للجميع في بيئة تعليمية

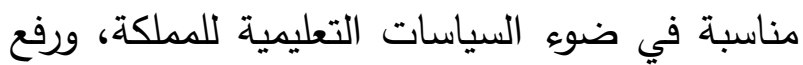

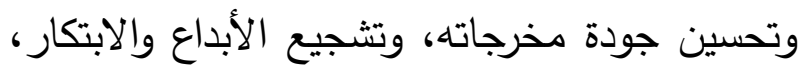
وتتمية الشراكة المجتمعية، والارتقاء بمهارات وقدرات منسوبي المؤسسات التعليمية من طلبه ومدرسين

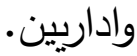
وتعتمد رؤية السعودية (·r.r) على ثلاثة محاور رئيسية تتكامل مع بعضها في سبيل تحقيق أهداف

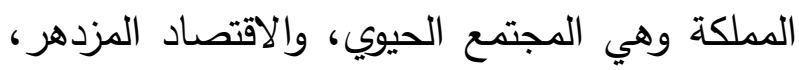
والوطن الطموح، وتمثل هذه المحاور أساساً متيناً لتحقيق هذه الرؤية وتأسيس قاعدة قوية للازدهار الاقتصادي والاجتماعي والتعليمي، وتنظر إلى لى العنصر البشري على أنه أهم ثروة يملكها الوطن ومن التعليم والتأهيل سيكون الثعب السعودي في مقدمة دول العالم، كما تركز الرؤية على ضرورة تطوير المنظومة التعليمية والتربوية بجميع مكوناتها؛

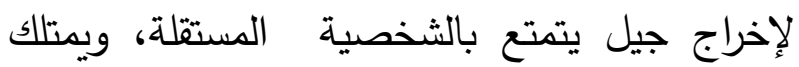
المعارف والمهارات والسلوكيات متصفاً بروح المبادرة

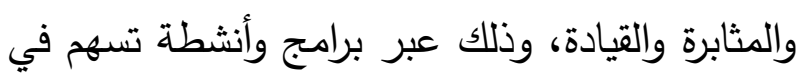
تمكين تلك المنظومة لتحقيق ذلك. كما تركز الرؤية على البعدين الديني والتاريخي للمكلة العربية السعودية وأهمية إبرازها واستثمارها 


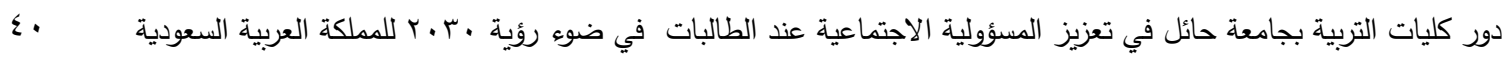

- تعمل على تتمية المهارات الشخصية العملية والعلمية للشباب، فالمشاركة في الاعمال الاجتماعية والتطوعية يؤدي إلى إكساب الشباب العديد من الخبرات التي تتمي مهاراتهم الشخصية والسلوكية وبالتالي جعلهم أكثر قدرة على إفادة مجتمعهم. - إتاحة الفرصة للشباب للتعبير عن آرائهم وأفكارهم في القضايا العامة التي تهم المجتمع، توفير فرص للشباب بأداء الخدمات بأنفسهم وحل المشكلات بجهدهم الشخصي، وهذا يعد استثماراً هاماً لطاقات الثباب للنهوض بالمجتمع. - توفير فرص للشباب للمشاركة في تحديد الأولويات التي يحتاج إليها المجتمع والمشاركة في اتخاذ القرارات.

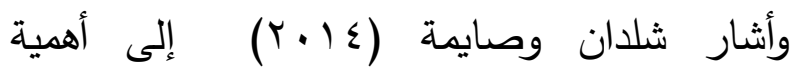
المسؤولية الاجتماعية في أنها تعد حاجة ملحة، ومطلبا مهما في عملية اعداد الأفراد في المجتمعات مختلفة؛ لتتحمل واجباتها تجاه الجماعة التي ينتمون إليها، والمجتمع الذي يعيشون فيه، إذ أن الارتقاء والتقدم الحضاري بالمجتمع مرتبط ارتباطا وثيقا بدرجة وعي الفرد بمسؤولياته الاجتماعية، ودرجة اهتمامه للقيام بها، كما أن المسؤولية الاجتماعية تؤدي دوراً مهماً في استقرار الحياة للأفراد والمجتمعات، حيث تعمل على صيانة نظم المجتمع، وتحفظ قوانينه وحدوه من الاعتداء، ويقوم كل فرد بواجبه ومسؤوليته نحو نفسه ونحو مجتمعه، ويعمل
التتمية المستدامة داخل الحرم الجامعي، علاوة على الخدمات الاجتماعية والبرامج التربوية للطلاب خارج الحرم الجامعي (محمد، 7 ( • ب). ولقد تعددت مفاهيم المسؤولية الاجتماعية، وتتاول الباحثين المفهوم من زوايا متعددة، ويعرف قاسم

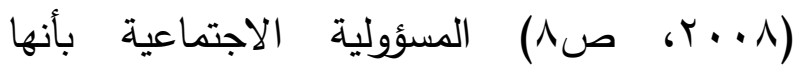
"مسؤولية الفرد عن نفسه ومسؤوليته اتجاه أسرته وأصدقائه واتجاه دينه ووطنه من خلال فهمه لدوره في تحقيق أهدافه واهتمامه بالآخرين من خلال علاقاته الإيجابية ومشاركته في حل مشكلات المجتمع وتحقيق الأهداف العامة". وعرفها شويدح

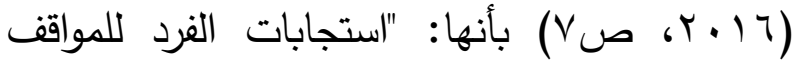
المختلفة، والتي تعبر عن مدى إدراكه ووعيه بأنه مسؤول عن نفسه وما يصدر عنه من أقوال وأفعال، ومدى فهمه لدوره الاجتماعي المتوقع منه، ومعرفة ماله sن حقوق وما عليه من واجبات تجاه أهله ومجتمعه، ومن خلال تعاونه مع الأخرين وعلاقاته الإيجابية في المساهمة في حل مشكلات المجتمع". وتهدف المسؤولية الاجتماعية إلى تحقيق أهداف

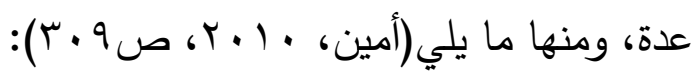
- العمل على تعزيز وانتماء ومشاركة الشباب في مجتمعه، فالثباب الذين يشاركون في برامج المسؤولية الاجتماعية يدركون أنهم ينتمون لهذا المجتمع، ويتحملون قدراً من المسؤولية تجاه

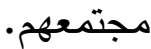


ما عليه في سبيل النهوض بأمانته الملقاة على وامهات ومعلمين ومعلمات، وعدم إشراك الثباب في

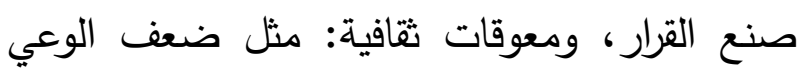
عاتقه.

بمفهوم وفوائد المشاركة في برامج المسؤولية الاجتماعية، وقلة التعريف بالبرامج والأنشطة ذات

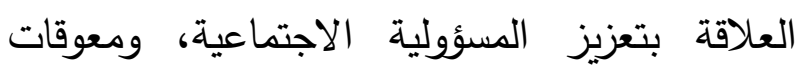
اقتصادية: وهي المعوقات ذات الجانب الاقتصادي والتي تحول المؤسسات من تنفيذ برامج المسؤولية

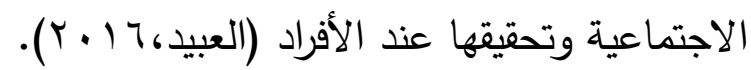

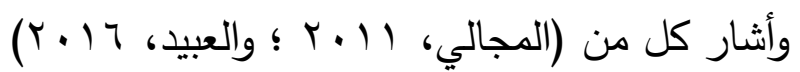
إلى أن للمؤسسات التربوية تؤدي دوراً في تعزيز المسؤولية الاجتماعية لدى طلابها من خلال: - اعداد الطلاب فكرياً وعلمياً للقيام بالأعمال ملهال

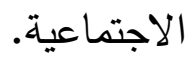
- تتمية قدرات الطلاب للتعامل مع المجتمع بكافة اطيافه واتجاهاته وسلوكياته، ومعايشة التغيرات الاجتماعية والثقافية والتقنية الناجمة عن التطورات

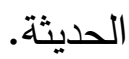

- تشجيع الطلاب على الإبداع من خلال المشاركة بالبرامج والأعمال التطوعية. - تدريب الطلاب على التعامل الايجابي مع وسائل

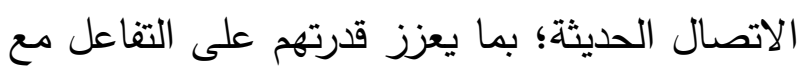
المجتمع وتعميق التواصل بين أفراده. - تتمية روح الفريق الواحد والإحساس بالمسؤولية

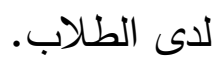
- تعزيز الانتماء والتعايش مع المجتمع وفق أسس علمية.

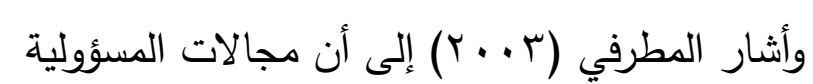
الاجتماعية يمكن حصرها في التالي: - مسؤولية الفرد تجاه أسرته : وتعني بالتزامات الفرد تجاه أسرته وأقاربه وجيرانه ومنزله وما يحويه من أفراد. - مسؤولية الفرد تجاه المؤسسة التعليمية التي ينتمي إليها: وتعني التزامات الفرد تجاه مؤسسته التعليمية

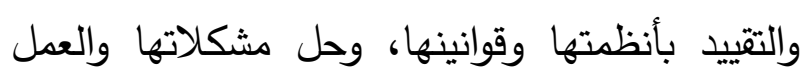
على تحسين بيئتها التعليمية وتطويرها. - مسؤولية الفرد تجاه مجتمعه الذي يعيش فيه: وتعني التزامات الفرد تجاه مجتمعه، وحل مشكلاته المختلفة، وتجاه الممتلكات والمرافق العامة والخاصة،

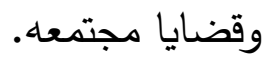
- مسؤولية الفرد تجاه وطنه: والمتمثل في الحفاظ على وطنه، والمحافظة على بقائه، وتماسك بنيانه، وتتمية الشعور بالولاء والانتماء اليه. ومن معوقات المسؤولية الاجتماعية، المعوقات

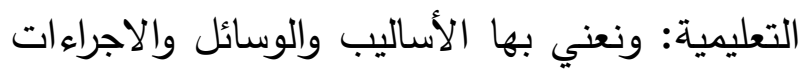
والممارسات ذات الصبغة التعليمية أو التربوية والتي تحول دون التفعيل الأمثل للمسؤولية الاجتماعية،

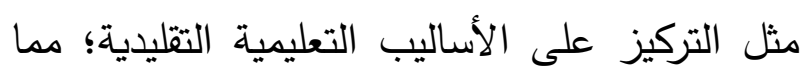
أضعف الهدف التربوي الاجتماعي، وعدم وضوح السياسات التعليمية التقليدية، وندرة المشاركة ببرامج المسؤولية الاجتماعية من قبل القدوات الحية من آباء 
والاقتصادية لأي مجتمع، من خلال إعداد الكوادر

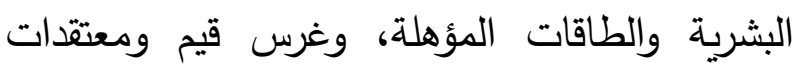
المجتمع في نفوس طلبتهم، وتكوين اتجاهات ايجابية

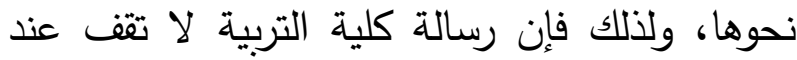
الإعداد العلمي للطلاب المعلمين، وانما الإعداد التربوي الذي يؤهلهم للقيام بمهماتهم ورسالتهم خير قيام ، وغرس القيم الدينية والثقافية والاجتماعية في لئي نفوس طلبتهم، ومن أهم القيم التي يجي أن يكتسبها طلبة كلية التربية هو الإحساس بالمسؤولية الإنية الاجتماعية، فمن خلال هذا الاحساس تنضبط عنده القيم الأخرى، مثل الالتزام بالعمل والحرص على الإسلى

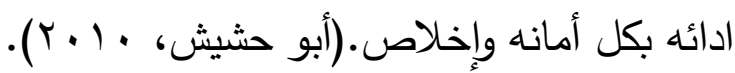

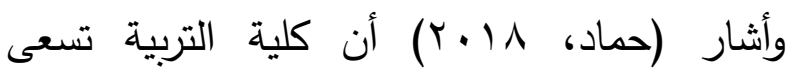
لتحقيق أهداف مسؤولياتها الاجتماعية والتي تتمثل في تطوير برامجها الأكاديمية لإعداد المعلمين القادرين على المشاركة المجتمعية وتنمية شخصيته، وإكسابهم اتجاهات ايجابية نحو المجتمع، وتزويدهم بالخبرات والمهارات التي تمكنه من القيام بدوره الوظيفي الذي يتوقعه الدجتمع منه، وتتمية قدرتهم على الوفاء بمسؤولياته الاجتماعية تجاه مجتمعله، كما تعمل كلية التربية على توفير البرامج والأنشطة الموجهة نحو المجتمع من خلال توفير الأمكانات البحثية والمعطلية لحل مشكلات المجتمع، وتتقديم

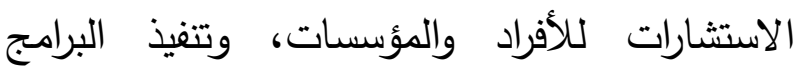
التأهيلية للطلاب وللعاملين بحقل التربية والتعليم.
- تعزيز دور أعضاء التدريس والطلاب في التخطيط والإعداد للأنثطة والبرامج اللاصفية؛ التي تنمي ميولهم ورغباتهم وتثبع حاجاتهم. - بناء المقررات الدراسية لتسهم في الدحافظة على العي القيم والمبادئ الاسلامية، وتعزيز المسؤولية الاجتماعية لاى طلابها.

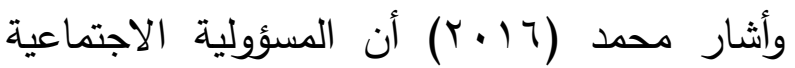
للجامعة نحو طلابها تتحقق من خلال ما يلي: العمل على تثقيف الطالب وإكسابه المهارات الثخصية والاجتماعية التي تجعله قادراً على حل المشكلات، واتخاذ القرار، والتواصل الفاعل مع التاعل المجتمع، من خلال المناهج والأنشطة الجامعية، والدروات ووش العمل والندوات، تتمية ثُقافة العمل التطوعي لاى الطلاب، مثل تخصيص أيام لزيارة

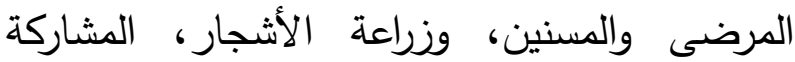
بالبحوث الدتعقة بالقضايا والمشكلات التي يعاني الكاني منها المجتمع، الاهتمام بالموهوبين من الطلاب وتتمية قدراتهم من خلال رعايتهم ودعمهم مادياً ومعنوياً، الاهتمام بالرعاية الصحية للطلاب من وناته خلال تطوير برامج الرعاية الطبية، مساعدة الطلاب غير القادين مادياً من خلال الدعم المالي وتوفير المشروعات الصغيرة. وتعد المسؤولية الأولى لكلية التربية بشكل عام هي التي إعداد المعلم واكسابه المعارف والمهارات التي تمكنه من إعداد الأجيال القادمة، لذلك يعد دور كلية التربية دوراً محورياً في منظومة التعليم والتتمية الاجتماعية 
الرياضية للبنات في الإسكندرية تسهم في تنمية

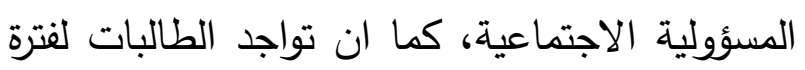
طويلة معاً بشكل جماعات يؤدي إلى شعورهن بالولاء والانتماء للجماعة وللجامعة والمجتمع. وفي دراسة المومني (2011) التي هدفت إلى ولى التئي التعرف على المسؤولية الاجتماعية لدى طلبة كلية الحصن الجامعية وعلاقتها بدافعية الإنجاز ، وتكونت

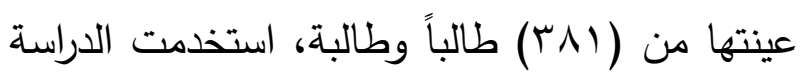
المنهج الوصفي، وبينت نتائج الدراسة أن درجة النة النئ المسؤولية الاجتماعية جاءت متوسطة على الأداة ككل، وبدرجة عالية على بعدي المسؤولية الوطنية

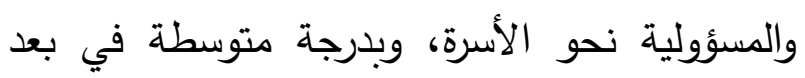
المسؤولية الثخصية والمسؤولية نحو الأصدقاء، والمسؤولية نحو الحي والمجتمع، كما بينت النتائج عدم وجود فروق ذات دلالة إحصائية في تقديرات

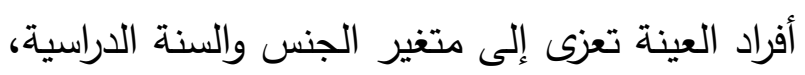
ووجود علاقة ارتباطية بين المسؤولية الاجتماعية

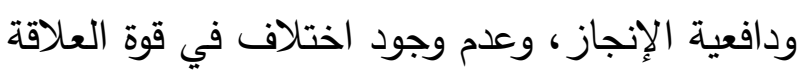
ارتباطية بين المسؤولية الاجتماعية ودافعية الإنجاز باختلاف متغيري الجنس والمستوى الدراسي. أما دراسة عوض، وحجازي (2011) التي هدفت

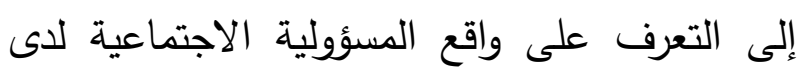
طلبة جامعة القد المفتوحة ووضع تصور مقترح

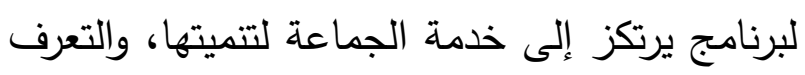
على الصعوبات التي تحد دون تحقيقها، وتكونت

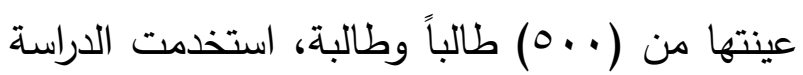

ويمكن القول من كل ما مضى أن المسؤولية الاجتماعية تمثل مطلباً حيوياً في إعداد الأفراد للقيام

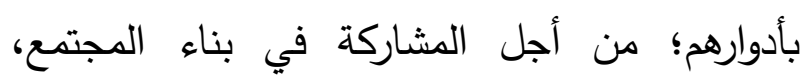

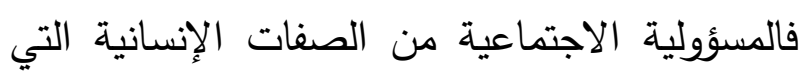
يجب غرسها داخل الفرد، حيث أن الفرد المتسم بتحمل المسؤولية الاجتماعية يحقق الفائدة لجميع أفراد المجتمع. ونظراً لأهمية موضوع المسؤولية الاجتماعية عند طالبات كلية التربية بجامعة حائل، لونطية

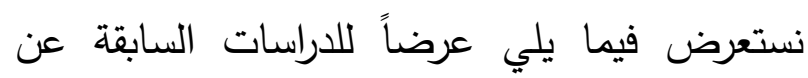
الموضوع، وذلك على النحو الآتي:

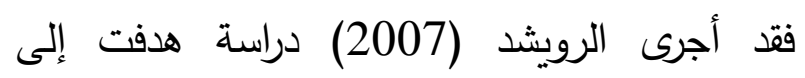
التعرف على مستوى الحرية، والمسؤولية الاجتماعية لاى طلاب كلية التربية الأساسية بدولة الكويت،

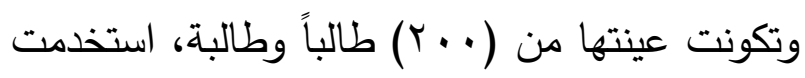

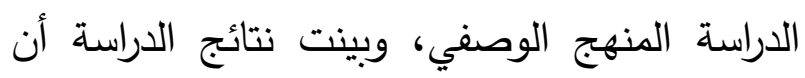
الطلاب كان لديهم توجهاً ايجابياً نحو المسؤولية

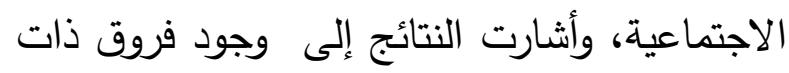

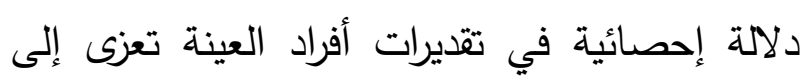

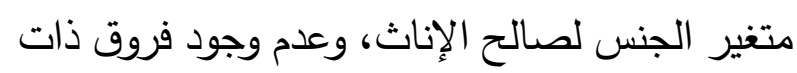

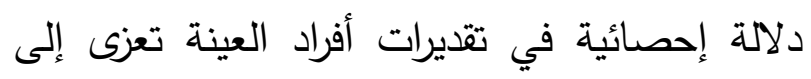
متغير الفصول الدراسية.

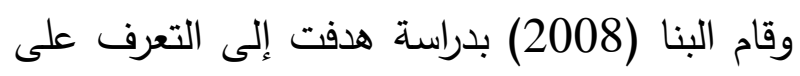
دور كلية التربية الرياضية للبنات في الإسكندرية في تنمية المسؤولية الاجتماعية لدى الطلبات، وتكونت

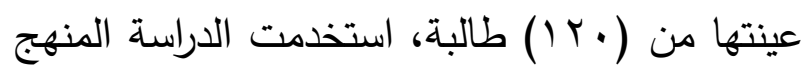
الوصفي، وبينت نتائج الدراسة أن برامج كلية التربية 


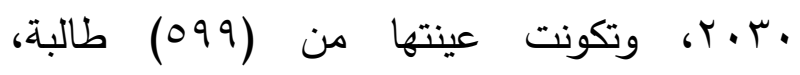
استخدمت الدراسة المنهج الوصفي، وبينت نتائج الدراسة أن درجة المسؤولية الاجتماعية لاى طالبات الداته

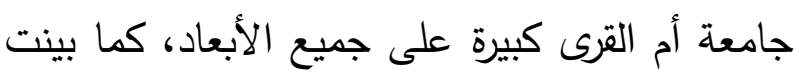

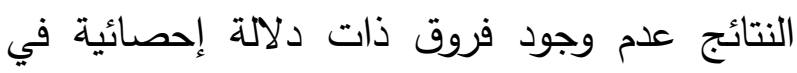

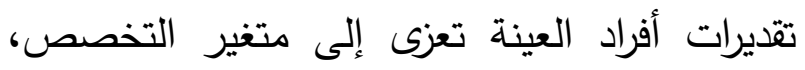
ووجود فروق ذات دلالة إحصائية في تقديرات أفراد

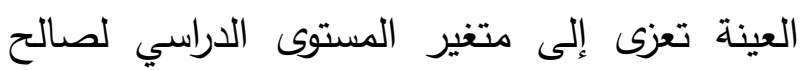
المستوى الثامن. وفي دراسة الرشيدي(2017) التي هدفت إلى التعرف على دور كلية التربية الأساسية في تتمية

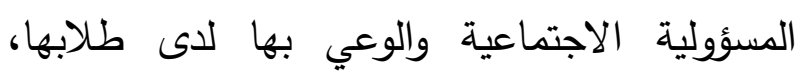

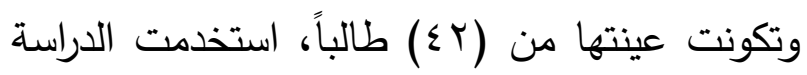

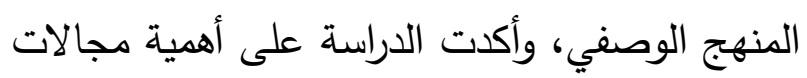

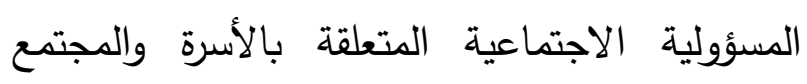
والهيئة العام للتعليم التطبيقي، وان كلية التربية الأساسية عليها قدر كبير من المسؤولية تجاه طلابها لإكسابهم العادات والمعاملات الحسنة، وأن تأثير كلية التربية الأساسية يقتصر فقط على الجانب اللفظي دون الجانب العملي، وتحتاج كلية التربية الأساسية إلى إعادة نظر في المناهج الدراسية التي

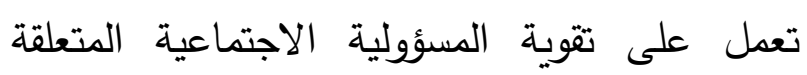
بالأسرة، وتدني الترابط بين كلية التربية الأساسية وبين المؤسسات المجتمعية. وعلى صعيد آخر أجرى الوادعي (2018) دراسة

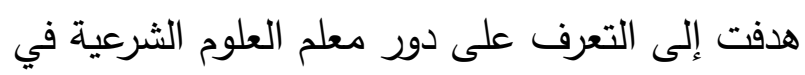

المنهج الوصفي، وبينت نتائج الدراسة أن درجة المسؤولية الاجتماعية لدى طلبة جامعة القدس لفئس

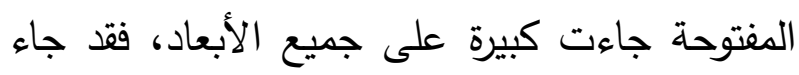
بعد المسؤولية الجماعية اولاً، ثم بعد المسؤولية الوطنية، ثم بعد المسؤولية الدينية والأخلاقية، وأخيرا بعد المسؤولية الثخصية، كما بينت النتائج عدم وجود فروق ذات دلالة إحصائية في تقديرات أفراد العينة تعزى إلى متغير الجنس والسنة الدراسية، ووجود فروق ذات دلالة إحصائية في تقديرات أفراد

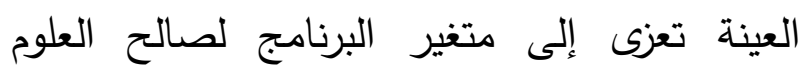
الإدارية. وأجرى جابر ، والمهدي (2011) دراسة هدفت إلى التعرف على دور الجامعات في تعزيز المسؤولية الاجتماعية لاى طلبتها، دراسة ميدانية مقارنة بين

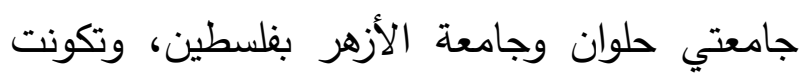

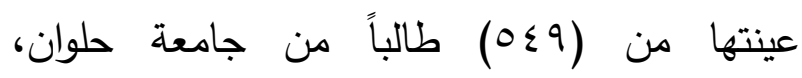

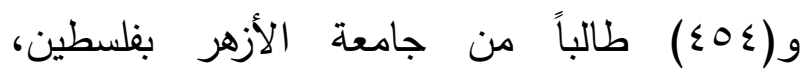
استخدمت الدراسة المنهج الوصفي، واقترحت الدراسة مجموعة من الآليات لتفعيل المسؤولية، ومن أهمها:

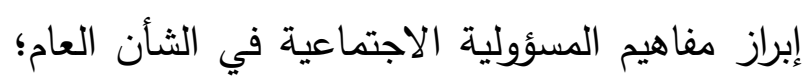
من خلا البرامج والماهج الأكاديمية والأنشطة الطلابية، تضمين قيم وأخلاقيات المسؤولية الاجتماعية في رسالة الجامعة وخطتها الاستراتيجية. كما أجرى عرفات، والعمودي (2017) دراسة هدفت إلى التعرف على دور جامعة أم القرى في تعزيز

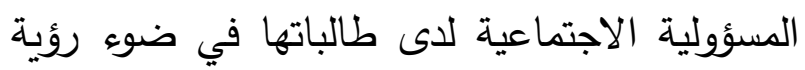


الشكلات الأخلاقية داخل حرم الكلية وطرحها امام الطلبة، ضعف مناقثة أعضاء التدريس طلابهم للقضايا والمستجدات ومعالجتها تربوياً، وأشارت النتائج ايضاً أن السبل لتفعيل التنمية الاجتماعية جاءت بدرجة عالية. وأخيراً في دراسة حماد (2018) التي هدفت إلى لى الته التعرف على دور كلية التربية في جامعة شقراء في

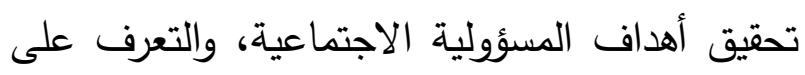
الصعوبات التي تحد دون تحقيقها، وتكونت عينتها من (· (1) عضو هيئة تدريس، استخدمت الدراسة المنهج الوصفي، وبينت نتائج الدراسة أن موافقة هنئه العينة بدرجة كبيرة على المحور المتعلق بالبرامج الأكاديمية التي تقدمها الكلية، وموافقتهم إلى حد ما لإنها على الأنشطة الموجهة نحو المجتمع، وأن أبرز

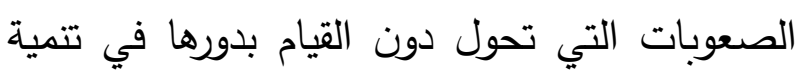
المسؤلية الاجتماعية تكمن في النواحي الإدارية وثقافية وتتظيمية وتمويلية.

\section{مشكلة الدراسة}

يشهر العالم اليوم الكثير من التغيرات والتحديات العالمية في النواحي العلمية والاقتصادية والاجتماعية

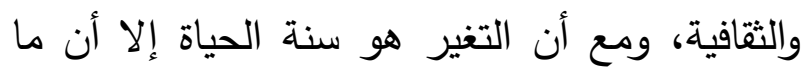
يميز هذه المتغيرات في عصرنا الحديث عن إن هيز التغيرات السابقة، هي سرعة التغير من ناحية وشموليته وعالميته، وتعدد أبعاده من ناحية أخرى،

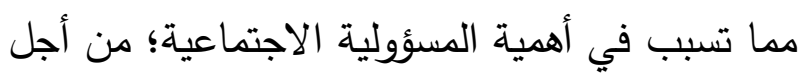

تعزيز مفاهيم المسؤولية الاجتماعية لدى طلاب المرحلة الثانوية من وجهة نظر مشرفي العلوم

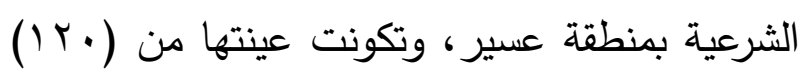

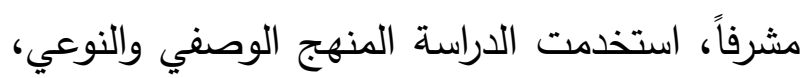

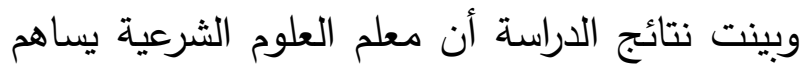
بدرجة كبيرة في حث الطلاب على احترام الأنظمة

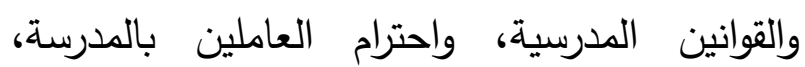
وتوعي الطلاب المثل والأفكار والقيم السائدة بالمجتمع، وتعزيز التفاعل الإيجابي مع مختلف ولفي ولفي

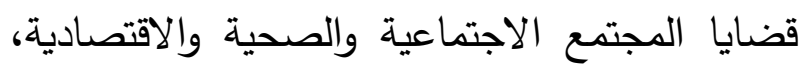

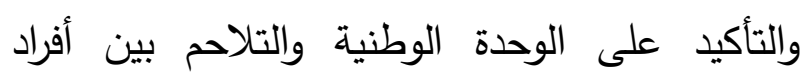

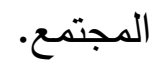

وفي دراسة الهويش (2018) التي هدفت إلى التعرف على دور كلية التربية في جامعة شقراء في تعزيز مسؤولية طالبها الاجتماعية وسبل تفعيلها من دن هنيه وجهة نظر طلابها، والتعرف على المعيقات التي تحول دون القيام بدورها في تنمية المسؤولية

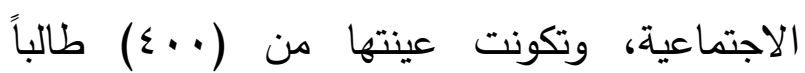
وطالبة، استخدمت الدراسة المنهج الوصفي، وبينت نتائج الدراسة أن دور كلية التربية في جامعة شقراء في تعزيز مسؤولية طالبها الاجتماعية جاء بدرجة كبيرة على جميع الأبعاد، فقد جاء بعد المسؤولية

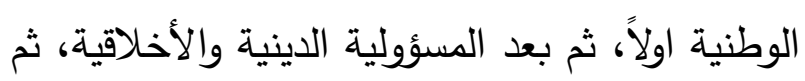
بعد المسؤولية الشخصية، وأخيرا بعد المسؤولية الجماعية، وأن أبرز المعيقات التي تحول دون القيام بدورها في تتمية المسؤولية الاجتماعية عدم تتاول 
شخصية ابنائها عن طريق تطوير المنظومة التربوية بجميع مكوناتها، واكساب الطلاب المعارف والمهارات والسلوكيات الحميدة؛ وتتمية المسؤولية الاجتماعية لايهم، بالإضافة إلى إكسابهح المعرفة والبحث العلمي؛ بهدف ايجاد مواطنين صالحين لهم دور فاعل في مؤسسات المجتمع، لتكون المخرجات التعليمية ذات شخصية مستقلة، تتصف بروح المبادرة والمثابرة والقيادة، ولديها القدر الكافي الذاتي والاجتماعي والثقافي، من خلال المشاركة في البرامج والأنشطة والفعاليات المختلفة. وجاء الاهتمام بهذا البحث انطلاقا من اهتمام رؤية •r.r. بالمرأة السعودية، وهي تشكل ما يزيد عن • \% من إجمالي الخريجين الجامعيين، لذا يجب الاهتمام بتتمية شخصيتها و واستثمار طاقاتها، وتمكينها من الحصول على الفرص المناسبة لبناء المجتمع.( رؤية المملكة • • •r). وتوصلت العديد من الدراسات التي تؤكد أهمية تتمية وتعزيز المسؤولية الاجتماعية عند طلاب وطالبات الجامعات، كدراسة عوض، وحجازي (2011) والتي أشارت الى أن درجة المسؤولية الاجتماعية لدى طلبة جامعة القدس المفتوحة جاءت كبيرة، ودراسة الهويش (2018) والتي أشارت إلى أن دور كلية التربية في جامعة شقراء في تعزيز مسؤولية طالبها الاجتماعية جاء بدرجة كبيرة، وأن أبرز المعيقات التي تحول دون القيام بدورها في تتمية المسؤولية الاجتماعية عدم تتاول المشكلات الأخلاقية داخل حرم الكلية وطرحها امام الطلبة، وأبرز السبل التي
إعداد مواطن قادر على تحمل المسؤولية، والتهيؤ للنهوض بمجتمعه. ومن المسلم به أن المؤسسات التعليمية تختلف عن بعضها البعض في عناصر نظمها، وبجميع مكوناتها تبعاً للرؤى والرسائل التي تتبناها، والأهداف التي تسعى لتحقيقها، فضلاً عن طبيعة تخصصاتها، وظروف بيئتها المختلفة، وطبيعة أنواع المخرجات، كل ذلك يجعل من تحقيق جودة المخرجات تلك المؤسسات امرا ليس سهلا، لذا أصبح توجه المؤسسات التعليمية إلى نظام العملية التعليمية الحديث الذي يولي اهتماما كبيرا بالمخرجات المستهدفة.

ولا يقتصر دور الجامعة على التدريس والبحث العلمي فقط، بل يمتد دورها في خدمة المجتمع من خلال تتمية المسؤولية الاجتماعية بما توفره من مناخ يتيح المشاركة الفاعلة في الرأي والعمل، وتتمي لدى الطلاب المشاركة والاسهام في بناء المجتمع وحل

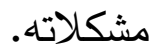

ولكلية التربية دور كبير وهام في بناء وتتمية شخصية طلابها، وغرس قيم ومعتقدات المجتمع، وتكوين الأفكار الايجابية في طلبتها، وتنمية المسؤولية الاجتماعية لايهم، التي هي الركيزة الأساسية في بناء المجتمع، وتظهر تلك الأهمية في دور الكلية في تتميتها وتعزيزها وتدريبهم عليها. وهذا ما تئكده رؤية .ب. رب للمملكة العربية السعودية على أهمية ترسيخ القيم الإيجابية في 
للمؤسسات التعليمية للطلاب تجاه مجتمعه ووطنه وجامعته؛ لما لها من دور فعال في تحقيق التقدم المجتمعي والتتموي، وتحقيق الريادة العالمية. r- تقيد الدراسة في إثراء المكتبة العربية وتزويد الباحثين بأطر نظرية حول دور كلية التربية

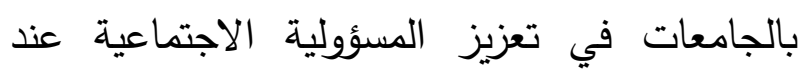

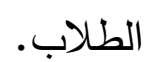

r- يمكن أن تفيد نتائج هذه الدراسة القائمين على التعليم ومتخذي القرار بدور المسؤولية الاجتماعية عند الطلبة الجامعيين في تعزيز القيم الايجابية والمهارات والسلوكيات المناسبة. ع - تطوير برامج والخطط والمناهج الدراسية لكلية التربية بجامعة حائل، بما يحقق أهداف المسؤولية الاجتماعية.

\section{أهداف الدراسةة:}

تسعى هذه الدراسة إلى:

- تسليط الضوء على واحدة من أبرز القضايا التربوية والاجتماعية في الجامعة وهي مفهوم المسؤولية الاجتماعية، لما لها من أهمية في تعزيز

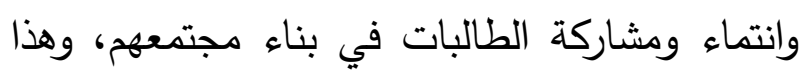
ما أكدت علية رؤية .r.r.r. - التعرف على دور كلية التربية بجامعة حائل في تعزيز المسؤولية الاجتماعية عند الطالبات. - الكثف عن مستوى المسؤولية الاجتماعية عند طالبات كلية التربية بجامعة حائل .
تساهم في تتمية المسؤولية الاجتماعية تفعيل المجالات الجامعية في مجال المسؤولية الاجتماعية. وفي دراسة الرشيدي (2017) والتي أثارت أن كلية التربية الأساسية عليها قدر كبير من المسؤولية

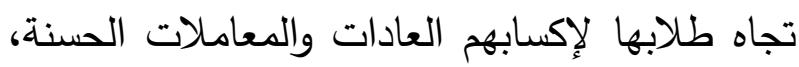

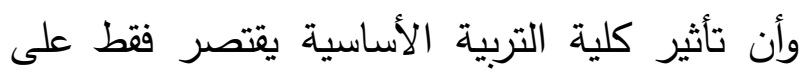

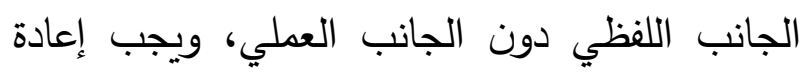
نظر في المناهج الدراسية في الكلية لتعزيز المسؤولية الاجتماعية. وأوصت دراسة لفيه فماد (2018) ضرورة تضمين المسؤولية الاجتماعية ومفاهيمها في البرامج التعليمية، والتوسع في البرامج والأنشطة لخدمة المجتمع. لذا فإن الدراسة الحالية تهدف الى لتحديد دور كلية التربية بجامعة حائل في تعزيز المسؤولية الاجتماعية عند الطالبات في ضوء رؤية ـ ـ • ب للمملكة العربية السعودية؛ للوقوف على الواقع الفعلي، وقياس مستوى

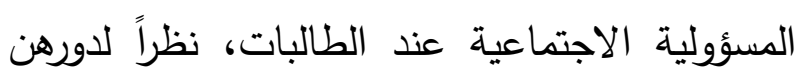
الحيوي في المجتمع السعودي، ومن هنا جاءت الدئه مشكلة الدراسة التي حاولت الإجابة عن السؤال الرئيسي التالي: ما دور كلية التربية بجامعة حائل في تعزيز

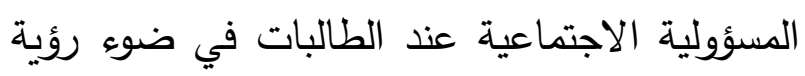

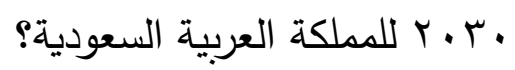
أهمية الدراسة:

تظهر أهمية الدراسة فيما يلي:

1- تأكيد الرؤية الوطنية للملكة العربية السعودية

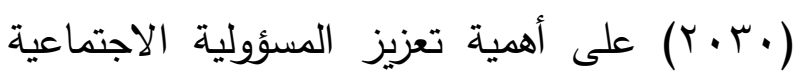


- الحدود المكانية: أجريت الدراسة على كلية جامعة حائل لفروع البنات. - الحدود الزمنية: طبقت هذه الدراسة خلال الفصل فينات

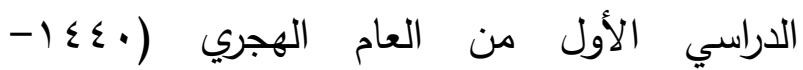
(ه) $\leqslant \leqslant 1$ - الحدود البشرية: اقتصرت الدراسة على طالبات الكلية التربوية بجامعة حائل في السنوات الدراسية الثانية والثالثة والرابعة.

\section{التعريفات الاصطلاحية والإجرائية:}

دور: هو مجموعة من الوظائف والمهام والأعمال

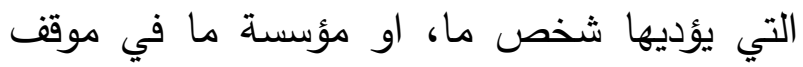
تفاعل معين، كما أنه نموذج يرتكز حوله بعض مض مونه

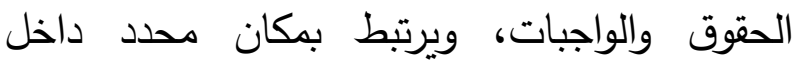

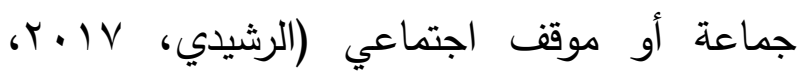
. (rT

المسؤولية الاجتماعية هي: "التزام الفرد الأخلاقي تجاه مجتمعه ووطنه الموجه لسلوكه، والمنظم لعلاقاته مع نفسه ومع الآخرين، من خلال معرفته

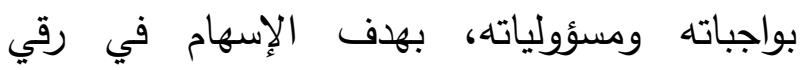
المجتمع وتطوره في جميع المجالات الحياة الاقتصادية والاجتماعية والأخلاقية والخيرية".

$$
\text { (الوادعي، 2018، } 7 \text { ؟). }
$$

المسؤولية الاجتماعية (إجرائيا): هي الأفعال والمهام والواجبات التي تؤديها طالبات كلية التربية بجامعة حائل داخل الجامعة وخارجها، والقدرة على ادائها في

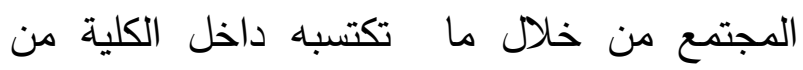

- التعرف على الاختلاف في مستوى المسؤولية الاجتماعية عند طالبات كلية التربية بجامعة حائل وفقا لتأثير متغيرات الدراسة. - تحديد أهم معوقات تعزيز المسؤولية الاجتماعية عند طالبات كلية التربية بجامعة حائل. - تقديم مجموعة من المقترحات لحل معوقات تعزيز المسؤولية الاجتماعية عند طالبات كلية التربية بجامعة حائل، وتسهم في غرس هذا المفهوم.

\section{تساؤلات الدراسة}

حاولت هذه الدراسة الإجابة عن الاسئلة التالية:

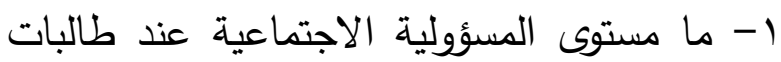
كلية التربية بجامعة حائل؟ ץ- هل توجد فروق دالة إحصائياً عند مستوى دلالة

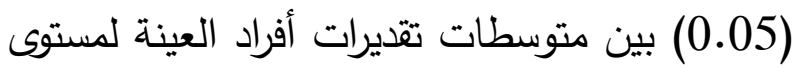
المسؤولية الاجتماعية عند طالبات كلية التربية

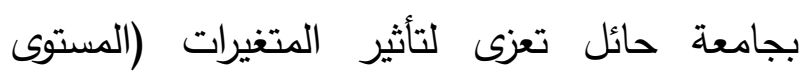
الأدراسي، التقدير)؟ r- ماهي معوقات تعزيز المسؤولية الاجتماعية عند طالبات كلية التربية بجامعة حائل؟ ع- ما المقترحات التي تسهم في تعزيز المسؤولية الاجتماعية عند طالبات كلية التربية بجامعة حائل؟ حدود الاراسة: تقتصر هذه الدراسة في حدودها على ما يلي: - الحدود الموضوعية: اقتصرت الدراسة في التعرف على دور كلية التربية بجامعة حائل في تعزيز المسؤولية الاجتماعية عند الطالبات. 
التربية بجامعة حائل في تعزيز المسؤولية الاجتماعية

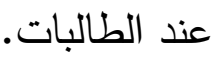
مجتمع الاراسة وعينته: تكوّن مجتمع الدراسة من جميع طالبات كلية

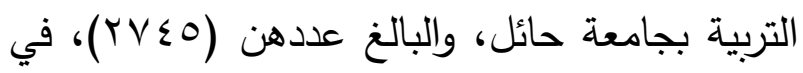

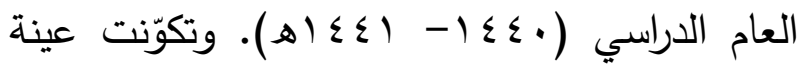
الدراسة من (ع آس) طالبة، وقد تم اختيارهن بالطريقة العشوائية البسيطة، وجدول ( (1) يوضح توزيع مجتمع بله الدراسة وعينته وفق متغيرات: السنة الدراسية،
برامج وأنشط مفيدة. وتتحدد في الدراسة الحالية بالدرجة التي تقدر بها طالبات كلية التربية بجامعة حائل لدور الكلية في تعزيز المسؤولية الاجتماعية لديهن، من خلال الاستجابة على الأداة التي أعدت

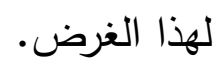
منهج الاراسة: استخدمت الدراسة المنهج الوصفي التحليلي الذي يعتمد على دراسة الظاهرة في الواقع، ووصفها، وتحليلها، والتعبير عنها كمياً وكيفاً، وذلك من خلال رصد واقع المشكلة البحثية وتحليلها لتبيان دور كلية ودئية الجدول (1): توزيع أفراد عينة الدراسة بحسب متغيرات الدراسة.

\begin{tabular}{|c|c|c|c|}
\hline النسبة المئوبة & التكرار & الفئات & المتغير \\
\hline 34.1 & 107 & الثانية & \\
\hline 30.9 & 97 & الثالثة & \\
\hline 35.0 & 110 & لمارابعة - الرابة & \\
\hline 8.9 & 28 & مقبول & \multirow{4}{*}{ التقدير } \\
\hline 27.4 & 86 & جيد & \\
\hline 33.1 & 104 & جيد جداً & \\
\hline 30.6 & 96 & متاز & \\
\hline 100.0 & 314 & المجموع & \\
\hline
\end{tabular}

الدرجات (1-r-r-צ-0). ولتحديد مستويات أداة الاراسة استجابات الطالبات، فقد تم تصنيف المتوسطات الحسابية، وفق المعيار التالي: (1, (1, فأقل) بدرجة من أجل بناء أدوات الدراسة، تم الرجوع إلى الى الى التهات

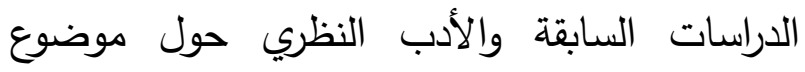

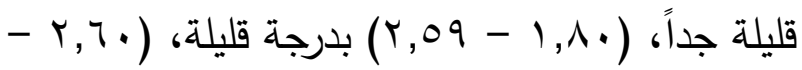
المسؤولية الاجتماعية، فقد تم بناء المقياس، والذي

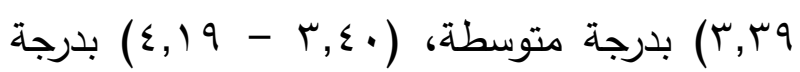
تكون من (YV) فقرة، وذلك بالاستعانة بالدراسات

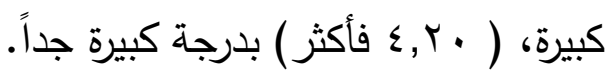

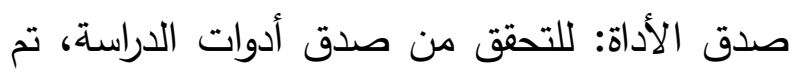

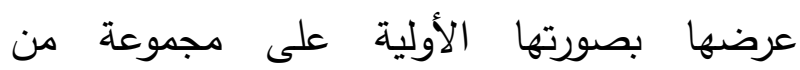
المحكمين في مجال الاختصاص(القياس والتقويم،

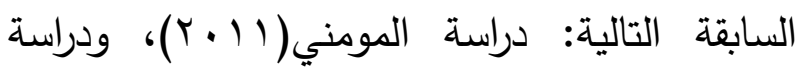
البنا(2008)، ودراسة عرفات، والعمودي (2017)، ودراسة حماد(2018)، وتكوّن المقياس من خمسة بدائل في الإجابة تم تصحيحها بإعطاء الفقرات 


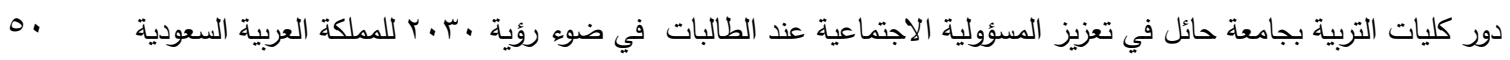

والإدارة التربوية، وطرق التدريس، وعلم النفس المقبولة ما بين(80- 100\%)، وتم العمل التربوي)، وطُلب منهم إبداء رأيهم واقتراح ملاحظاتهم بالملاحظات المقترحة. من حيث الصياغة اللغوية، ومناسبة الفترات لمحتوى ثبات الأداة: للتحقق من ثبات أدوات الدراسة، فقد تم موضوع الدراسة، وتراوحت نسبة الاتفاق على الفقرات استخدام معامل كرونباخ ألفا كما هو موضح في

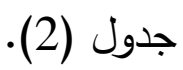

جدول (2): قيم معامل ثبات الاتساق الداخلي لأدوات الدراسة ومجالاتها.

\begin{tabular}{|c|c|}
\hline معامل الثبات & المجالات \\
\hline 0.88 & المسؤولية تجاه الجامعة \\
\hline 0.84 & المسؤولية تجاه المجتمع \\
\hline 0.89 & المسؤولية تجاه الوطن \\
\hline 0.92 & المسؤولية الاجتماعية ككل \\
\hline
\end{tabular}

تم استخدام معامل كرونباخ ألفا لحساب ثبات أداة نتائج الدراسة ومناقشتها: الدراسة، تراوحت قيم الثبات لمجالات المقياس ما السؤال الأول: ما مستوى المسؤولية الاجتماعية عند

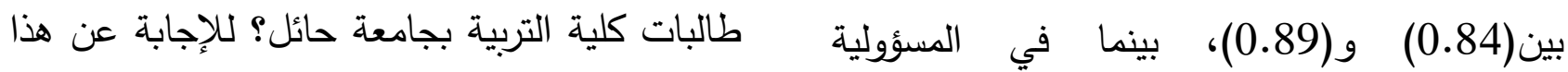

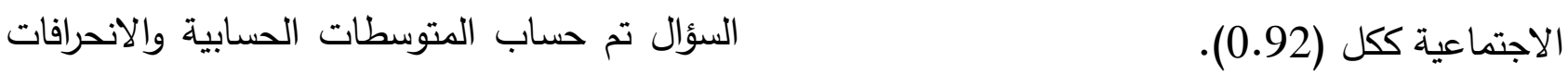
المعيارية والرتب لمستوى المسؤولية الاجتماعية عند طالبات كلية التربية بجامعة حائل، ويتبين ذلك من

$$
\text { خلال جدول (3). }
$$

جدول (3):المتوسطات الحسابية والانحرافات المعيارية والرتب لمستوى المسؤولية الاجتماعية عند طالبات كلية التربية بجامعة حائل على جميع المجالات والفقرات.

\begin{tabular}{|c|c|c|c|c|c|}
\hline المسؤولية & الانحراف المعياري & المتوسط & المجالات والفقرات & الرتبة & 5 \\
\hline & & & المجال الأول: المسؤولية تجاه الجامعة & & \\
\hline 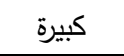 & 1.172 & 4.03 & التعامل مع المسؤولين والأعضاء والعاملين باحترام. & 1 & 1 \\
\hline 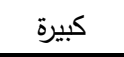 & 1.173 & 3.82 & توجيه الطالبات على الالتزام باللوائح والقوانين والأنظمة المعمول بها. & r & $\varepsilon$ \\
\hline 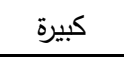 & 1.347 & 3.59 & تعريف الطالبات بالحقوق والواجبات المناطة بالطالبة الجامعي. & r & 1 \\
\hline 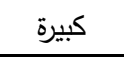 & 1.273 & 3.57 & اشعار الطالبات بأهمية ما يقومون به من أعمال اجتماعية داخل الكلية. & $\varepsilon$ & r \\
\hline 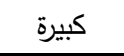 & 1.368 & 3.54 & حث الطالبات على المحافظة على مرافق الكلية من أثاث ولوازم. & 0 & 9 \\
\hline
\end{tabular}


هيفاء علي محمود طيفور

\begin{tabular}{|c|c|c|c|c|c|}
\hline متوسطة & 1.103 & 3.32 & توجيه الطالبات نحو للمشاركة في الأنشطة اللاصفية. & 7 & 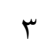 \\
\hline متوسطة & 1.241 & 3.29 & توجيه الطالبات إلى المواقع البحثية النافعة. & V & $\wedge$ \\
\hline متوسطة & 1.107 & 3.26 & تشجيع الطالبات على تكوين علاقات اجتماعية ناجحة مع زميلاتهن داخل & $\wedge$ & V \\
\hline \multirow[t]{2}{*}{ متوسطة } & 1.429 & 2.98 & حث الطالبات على ترشيد استخدام الكهرباء والماء داخل الكلية. & 9 & 0 \\
\hline & & & المجال الثاني: المسؤولية تجاه المجتمع & & \\
\hline 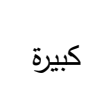 & 1.324 & 3.43 & توجه الكلية الطالبات على الالتزام بالعادات والتقاليد في المجتمع & 1 & 11 \\
\hline 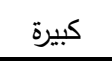 & 1.239 & 3.42 & توعية الطالبات بالقيم والمثل والأفكار السائدة في المجتمع. & $r$ & 1. \\
\hline متوسطة & 1.292 & 3.37 & تشجيع الطالبات على المشاركة في العمل التطوعي. & r & $1 \leq$ \\
\hline متوسطة & 1.377 & 3.22 & توعية الطالبات بالأخطار والمشكلات التي تواجه المجتمع. & $\varepsilon$ & ir \\
\hline متوسطة & 1.463 & 3.12 & حثهم على التفاعل الايجابي مع قضايا المجتمع كالفقر والبطالة. & 0 & ir \\
\hline \multirow[t]{2}{*}{ متوسطة } & 1.228 & 3.08 & توجيه الطالبات نحو المشاركة في أنشطة الجمعيات والمؤسسات الاجتماعية. & 7 & 10 \\
\hline & & & المجال الثالث: المسؤولية تجاه الوطن & & \\
\hline 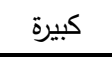 & 1.194 & 3.98 & تشجعني الكلية على المشاركة في المناسبات الوطنية التي تقيمها. & 1 & 17 \\
\hline 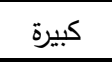 & 1.14 & 3.82 & تؤكد الكلية على الوحدة الوطنية والتلاحم بين أفراد المجتمع. & $r$ & IV \\
\hline 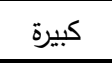 & 1.351 & 3.71 & تعرف الكلية طالباتها بتاريخ وطنهم، وكفاح آبائهم الأوائل. & r & 19 \\
\hline كبيرة & 1.208 & 3.63 & تبرز الكلية نجاحات المملكة في المجالات السياسية والاقتصادية & $\varepsilon$ & 11 \\
\hline 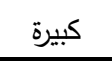 & 1.342 & 3.45 & تحذر الكلية الطالبات من خطورة الثائعات الغرضة وتحصينهم ضدها. & 0 & $r$. \\
\hline
\end{tabular}

يتضح من نتائج جدول (3) أن المتوسطات الحسابية لفقرات هذا المجال ما بين (3.08-

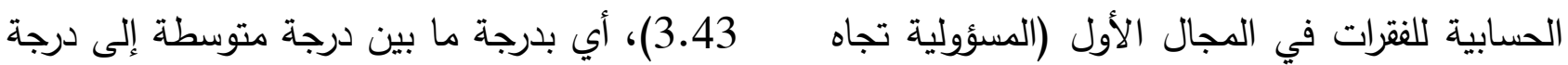

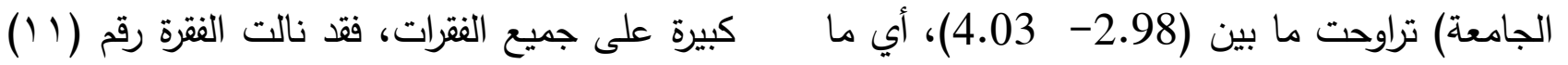
بين درجة قليلة إلى درجة كبيرة، فقد نالت الفقرة رقم ونصها " توجه الكلية الطالبات على الالتزام بالعادات

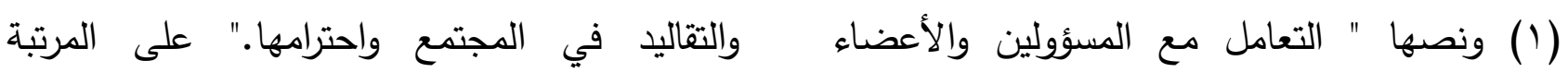

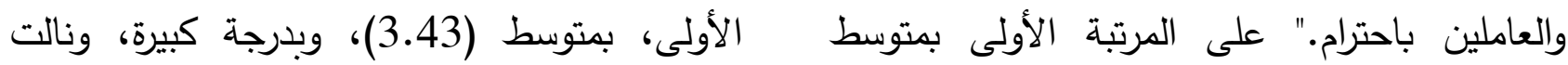

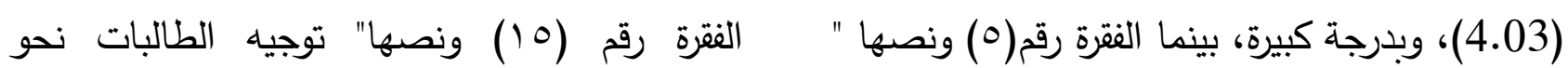

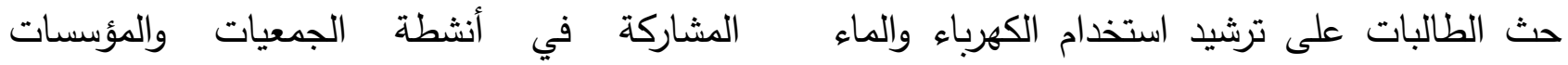
داخل الكلية." على المرتبة الأخيرة، بمتوسط الاجتماعية." على الرتبة الأخيرة، بمتوسط (3.08)، (2.98)، وبدرجة متوسطة، أما في المجال الثاني وبدرجة متوسطة، أما في المجال الثالث المسؤولية الثئه المسؤولية تجاه المجتمع تراوحت المتوسطات تجاه الوطن تراوحت المتوسطات الحسابية لفقرات 
الأولى، بمتوسط (3.98)، وبدرجة كبيرة، ونالت

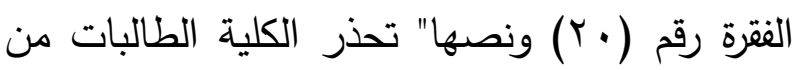
خطورة الثائعات الغرضة وتحصينهم ضدها." على الرتبة الأخيرة، بمتوسط (3.45)، وبدرجة كبيرة.
هذا المجال ما بين (3.45-3.98)، أي بدرجة

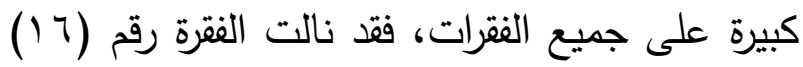
ونصها " تشجعني الكلية على المشاركة في المناسبات الوطنية التي تتيمها."، على المرتبة

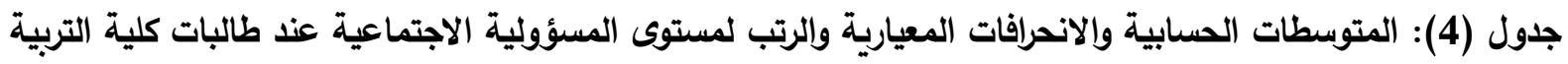
بجامعة حائل على جميع المجالات والأداة الكلية.

\begin{tabular}{|c|c|c|c|c|c|}
\hline درجة الممارسة & الانحراف المعياري & المتوسط الحسابي & المجالات & 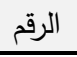 & 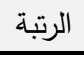 \\
\hline كبيرة & 1.051 & 3.72 & المسؤولية تجاه الوطن. & 3 & 1 \\
\hline كبيرة كبرة & .938 & 3.49 & المسؤولية تجاه الجامعة. & 1 & r \\
\hline متوسطة & 1.154 & 3.27 & المسؤولية تجاه المجتمع. & r & r \\
\hline 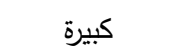 & .943 & 3.49 & المسؤولية الاجتماعية ككل. & & \\
\hline
\end{tabular}

يتضح من نتائج جدول (4) أن المتوسطات والاحتفاء به، وتعزيز روح الانتماء للوطن، وتتمية

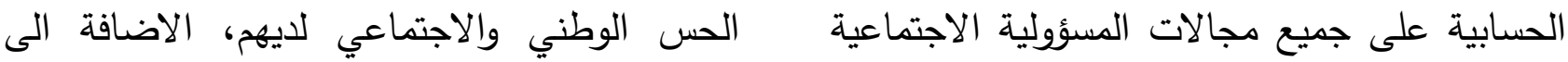
تنمية روح الولاء للوطن وغرس حب العمل وكذلك تعريفهن بمؤسسات بلدهم والنقاط المضيئة والانجازات الحضارية وضرورة المحافظة والدفاع لهربعات عنها، مما يزرع الثقة والإدراك لدى الطالهاتهات وربطهم بالمجتمع المحيط بهم مع تتمية شخصيتها

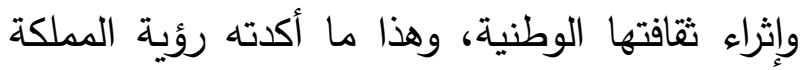

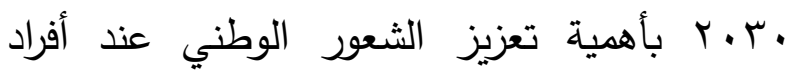
المجتمع السعودي، ثم جاء مجال المسؤولية تجاه الجامعة بالمرتبة الثانية وبدرجة كبيرة، وتعزو الباحثة النتيجة إلى اهتمام كلية التربية في غرس حب حبد النظام وروح المبادرة واحترام القانون من خلال التعليم بالقدوة قبل التعليم بالكلام، وتوجيههن على التعامل

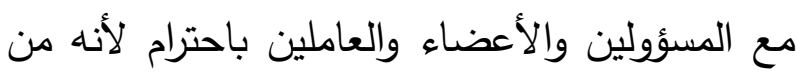

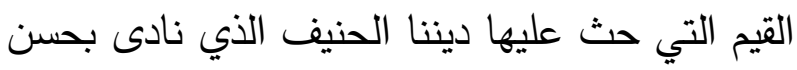

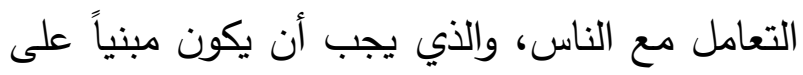

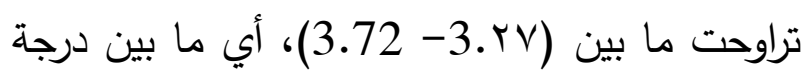
متوسطة إلى درجة كبيرة، فقد جاء مجال المسؤولية تجاه الوطن في المرتبة الأولى وبدرجة كبيرة، وتعزو الباحثة النتيجة إلى اهتمام الكلية التربوية بجامعة

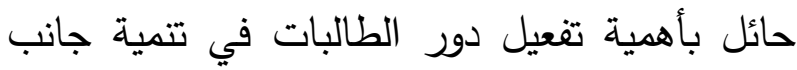
الحس الوطني في ظل الصراعات الثقافية الحالية والتيارات الفكرية المتناقضة، وانطلاقاً من مبادئ وقيم المملكة الحميدة التي تستمدها من القرآن والسنة

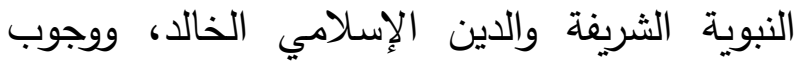

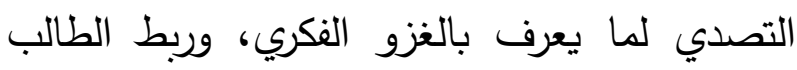
بالأرض والوطن والتراث والتاريخ والبيئة، وما نعيشه ولهن في وقتنا الحاضر من ازدهار وتقدم في المجالات كافة، وما يتطلبه الوضع الراهن من بذل التضحيات، وذلك من خلال مشاركة الطالبات بفعاليات كبيرة ووسائل متعددة ومختلفة لتعريفهم باليوم الوطني 
الأخلاق والمودة، وكذلك ضرورة المحافظة على ككل، جاء مستوى المسؤولية الاجتماعية عند طالبات كلية التربية بجامعة حائل كبيرة، وبمتوسط مرافق الكلية من أثاث ولوازم، مما يبني عندهن بلغ (3.49)، وتعزو الباحثة النتيجة إلى أن اتجاهات ايجابية نحو الجامعة، وتنمية الولاء الطالبات لديهن تتوع كبير في حس المسؤولية الاجتماعية تجاه الوطن والجامعة والمجتمع، مما يعمل على صقل شخصيتها، ورفع مستوى الوعي لايها، وتجعلها مستقلة في ذاتها، ويعزز من انتماءها ومشاركتها في مجتمعها، ويجعلها تدرك أنها تنمي لهذا المجتمع، ويتحملن قدراً من المسؤولية تجاه مجتمعها ووطنها وجامعتها. وهذا ما أكده المشرف

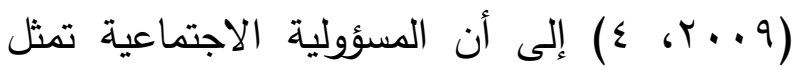

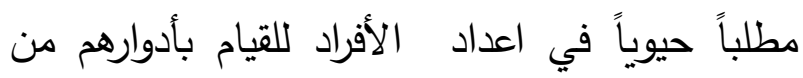
أجل المشاركة في بناء المجتمع، فالمسؤولية الاجتماعية من الصفات الإنسانية التي يجب غرسها داخل الفرد، حيث أن الفرد المتسم بتحمل المسؤولية الاجتماعية يحقق الفائدة لجميع أفراد المجتمع. وقد اتفقت نتائج هذه الدراسة مع كل من دراسة الهويش (2018) والتي أشارت أن دور كلية التربية في جامعة شقراء في تعزيز مسؤولية طالبها الاجتماعية جاء بدرجة كبيرة على جميع الأبعاد، ودراسة الرشيدي(2017) التي أكدت على أهمية مجالات المسؤولية الاجتماعية المتعلقة بالأسرة و المجتمع والهيئة العام للتعليم التطبيقي، واختلفت نتائج هذه الدراسة مع كل من دراسة المومني (2011) التي أشارت إلى أن درجة المسؤولية والانتماء للجامعة. وجاء مجال المسؤولية تجاه المجتمع بالمرتبة الثالثة وبدرجة متوسطة، وهذا يدل على أن دور كلية التربية بهذا المجال متوسط ولا بد من تفعليه، فبتفاعل الفرد مع المجتمع يتكون التماسك والتداخل والتشابك الاجتماعي بأشكاله الثقافية والاقتصادية، وبتأثير هذا التبادل والتفاعل للأدوار الاجتماعية، يحصل التكامل النفسي والاجتماعي للمجتمع ككل. فالفرد يحقق ذاته من خلال الجماعة والجماعة تحقق وجودها من خلال الجماعات في وحدتها الكلية لتشكل ديناميكية، وتعزو الباحثة النتيجة إلى كثرة المهام الإدارية والتدريسية الملقاة على كادر الكلية في الجانب الإداري والتدريسي، فيكون دورهم بهذا الجانب متوسطاً خصوصاً ما يتعلق بتشجيع الطالبات على المشاركة في العمل التطوعي في المجتمع، و حثهم على التفاعل الايجابي مع قضايا المجتمع كالفقر والبطالة، وهي من المسؤوليات التي يجب أن تنمى بشكل أكبر عند طالبات الكلية، كي تساعدهن على الارتقاء بتفكيرهن وتتمية الحس المجتمعي لايهن. ولا بد من ادراك أهمية إعداد الطالبات في المرحلة

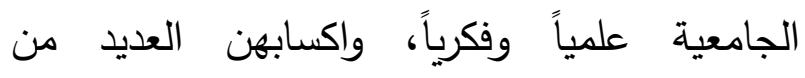
المهارات كمهارة الحوار والاتصال؛ ليساهم في حل الاجتماعية جاءت متوسطة. مشكلات المجتمع المختلفة. أما على مستوى الأداة 
السؤال الثاني: هل توجد فروق دالة إحصائياً عندالمستوى الدراسي، التقدير) ؟ للإجابة عن هذا مستوى دلالة (0.05) بين متوسطات تقديرات أفراد السؤال تم استخراج المتوسطات الحسابية والانحرافات العينة لمستوى المسؤولية الاجتماعية عند طالبات المعيارية حسب متغيرات الدراسة، كما في الجدول

كلية التربية بجامعة حائل تعزى لتأثير المتغيرات (0). جدول (5): المتوسطات الحسابية الانحرافات المعيارية لمستوى المسؤولية الاجتماعية عند طالبات كلية التربية بجامعة حائل حسب متغيرات الاراسة

\begin{tabular}{|c|c|c|c|}
\hline الانحراف المعياري & المتوسط الحسابي & فئات المتغير & المتغيرات \\
\hline 0.928 & 3.35 & الثانية & \multirow{3}{*}{ السنة الدراسية } \\
\hline 0.932 & 3.36 & الثالثة & \\
\hline 0.907 & 3.75 & الرابعة & \\
\hline 0.848 & 3.09 & مقبول & \multirow{4}{*}{ التقدير } \\
\hline 0.913 & 3.51 & جيد & \\
\hline 0.885 & 3.54 & جيد جداً & \\
\hline 1.025 & 3.53 & ممتاز & \\
\hline
\end{tabular}

يتضح من الجدول (0) أن هنالك فروق في الإحصائية بين المتوسطات الحسابية تم استخدام المتوسطات الحسابية والانحرافات المعيارية في تحليل التباين الثنائي، كما في جدول (T). استجابات عينة الدراسة، ولبيان دلالة الفروق جدول (6): تحليل التباين الثنائي للفروق بين المتوسطات الحسابية لتقديرات أفراد العينة على المسؤولية الاجتماعية حسب متغيرات الدراسة.

\begin{tabular}{|c|c|c|c|c|c|}
\hline مستوى الدلالة & قيمة ف & متوسط المربعات & درجات الحرية & مجموع المربعات & المتغيرات \\
\hline .000 & 7.865 & 6.669 & 2 & 13.339 & السنة الدراسية \\
\hline \multirow[t]{3}{*}{.159} & 1.739 & 1.475 & 3 & 4.424 & التقدير \\
\hline & & .848 & 308 & 261.182 & الخطأ \\
\hline & & & 314 & 4110.289 & المجموع \\
\hline
\end{tabular}

يتضح من نتائج جدول (6) وجود فروق دالة وجود فروق دالة إحصائياً عند مستوى (م=0.05) إحصائياً عند مستوى (م=0.05) بين المتوسطات بين المتوسطات الحسابية في لمستوى المسؤولية الحسابية في لمستوى المسؤولية الاجتماعية عندالاجتماعية عند طالبات كلية التربية بجامعة حائل طالبات كلية التربية بجامعة حائل على الدرجة على الدرجة الكلية، تعزى لاختلاف متغير التقدير. الكلية، تعزى لاختلاف متغير السنة الدراسية، وعدم 
ففي متغير التقدير تقسر الباحث هذه النتيجة؛ إلى والتآلف والجماعية، مما أتاح الفرص الايجابية لدعم

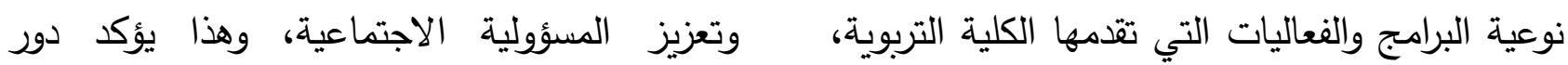
والتي تعزز عندهن مفاهيم المسؤولية الاجتماعية في الجامعة في تعزيز المسؤولية الاجتماعية في ضوهي

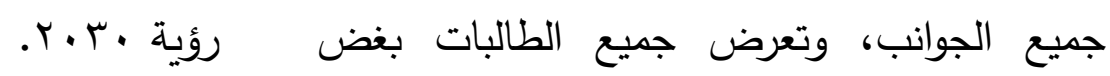
النظر عن تقديرهن الجامعي لمستوى واحد من أما في متغير السنة الدراسية، فبينت النتائج إلى لى

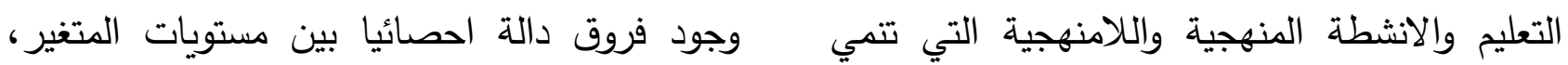
المسؤولية الاجتماعية لدى كل منهما، مما انعكس ولتحديد اتجاه الفروق، استخدمت الباحثة اختبار على مستوى المسؤولية الاجتماعية بغض النظر عن شفيه للمقارنات البعدية وكانت نتائجه على الثكل

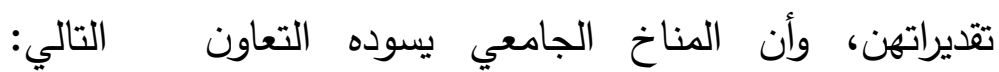

جدول (7):نتائج اختبار شيفيه للمقارنات البعدية للفروق بين تقديرات أفراد عينة الدراسة على الارجة الكلية للمسؤولية الاجتماعية تبعا لمتغير السنة الدراسية

\begin{tabular}{|c|c|c|c|c|c|}
\hline رابعة & ثالثة & ثانية & \multicolumn{2}{|c|}{ السنة الدراسية } & \\
\hline 3.75 & 3.36 & 3.35 & المتوسط الحسابي & & \\
\hline & .29 & & 3.35 & ثانية & \\
\hline .19 & & & 3.36 & ثالثة & الدرجة الكلية للمسؤولية الاجتماعية \\
\hline & & $.48 *$ & 3.75 & رابعة & \\
\hline
\end{tabular}

في حس المسؤولية الاجتماعية تجاه الوطن والجامعة

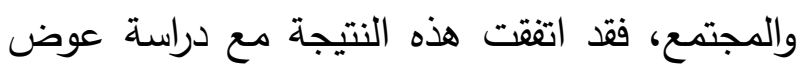

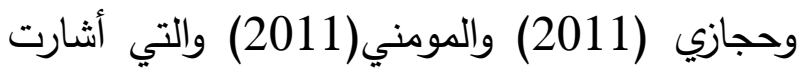
الى وجود فروق دالة إحصائياً في مستوى المسؤولية ولية

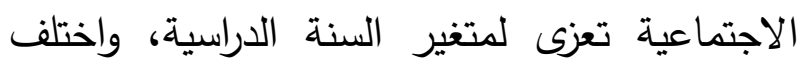
هذه النتيجة مع دراسة عرفات والعمودي (2017) والتي أشارت الى عدم وجود فروق دالة إحصائياً في مستوى المسؤولية الاجتماعية تعزى لمتغير السنة

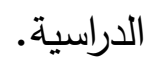
السؤال الثالث: - الث يتضح من الجدول رقم (V) من خلال إجراء اختبار شيفيه للمقارنات البعدية إلى وجود فروق دالة احصائيا بين متوسطات تتديرات طالبات السنة الرابعة من جهة وطالبات السنة الثانية من جهة لهنيات أخرى وذلك لصالح تقديرات طالبات السنة الرابعة. فتعزو الباحثة هذه النتيجة إلى وصول طالبات السنة الرابعة إلى مستوى كبير في المسؤولية الاجتماعية؛

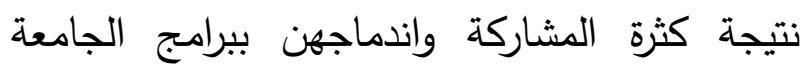
وفعاليتها الوطنية والاجتماعية، فأصبحن أكثر وعياً

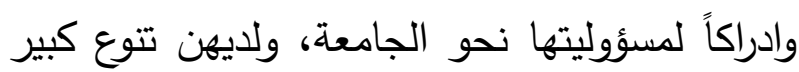


المعيارية والرتب لكل فقرة من فقرات المقياس، ويتبين ذلك من خلال الجدول رقم (8).
ماهي معوقات تعزيز المسؤولية الاجتماعية عند طالبات كلية التربية بجامعة حائل ؟ للإجابة عن هذا فراني السؤال تم حساب الأوساط الحسابية والانحرافات

جدول(8)المتوسطات الحسابية والانحرافات المعيارية والرتب لمعوقات تعزيز المسؤولية الاجتماعية عند طالبات كلية التربية بجامعة حائل على جميع الفقرات والأداة الكلية

\begin{tabular}{|c|c|c|c|c|c|}
\hline درجة المعوقات & 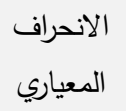 & المتوسط & 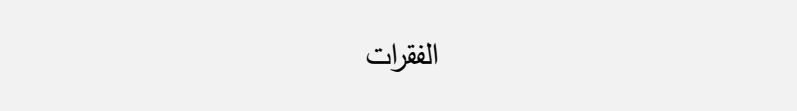 & 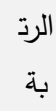 & r \\
\hline كبيرة & 1.209 & 3.63 & عدم وجود قنوات ووسائل اتصال واضحة ومحددة بين الكلية والمجتمع & 1 & 2 \\
\hline كبيرة & 1.183 & 3.48 & ضعف الدافعية عند الطلاب في المشاركة في النشاطات الاجتماعية & 2 & 4 \\
\hline كبيرة & 1.172 & 3.46 & عدم فهم معنى المسؤولية المجتمعية لدى البعض من أولياء الأمور . & 3 & 8 \\
\hline متوسطة & 1.218 & 3.32 & قصور وسائل الإعلام داخل الكلية في نشر ثقافة المسؤولية المجتمعية. & $\varepsilon$ & ० \\
\hline متوسطة & 1.163 & 3.31 & قلة البرامج التدريبية في مجالات المسؤولية الاجتماعية. & 5 & r \\
\hline متوسطة & 1.289 & 3.27 & ضعف التشجيع في المشاركة بالأعمال التطوعية والخيرية بالمجتمع. & 6 & 1 \\
\hline متوسطة & 1.184 & 3.1 & ضعف المقررات والمناهج الدراسية في تعزيز المسؤولية الاجتماعية. & 7 & 6 \\
\hline ضعيفة & 1.184 & 2.21 & قلة وجود الموارد المالية التي تمكن الكلية من القيام بالمسئولية المجتمعية & 8 & $\mathrm{v}$ \\
\hline متوسطة & 0.859 & 2.83 & 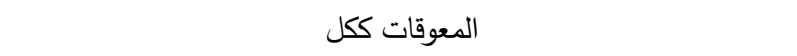 & & \\
\hline
\end{tabular}

المشاركة في النشاطات الاجتماعية المختلقة."

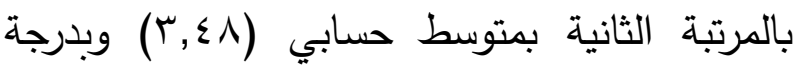

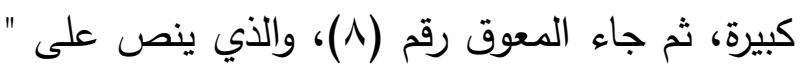

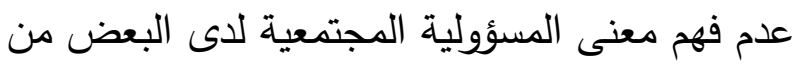

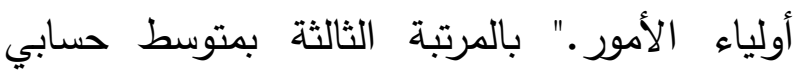

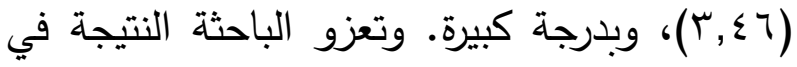
عدم وجود قنوات ووسائل اتصال واضحة ومحددة بين الكلية والمجتمع الخارجي، إلى انشغال الكلية

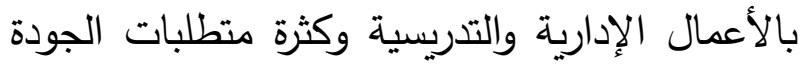

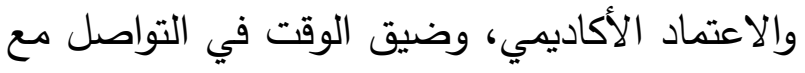

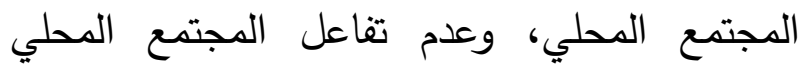
بدرجة مناسبة مع الكلية في المشاركة في الفعاليات والأنشطة، وتعزو الباحثة النتيجة في ضعف في الدئاركة في الدعالية
يشير جدول(^) إلى أن معوقات تعزيز المسؤولية الاجتماعية عند طالبات كلية التربية بجامعة حائل جاءت بدرجة متوسطة بمتوسط حسابي(r,rV)، وهذا يدل على الرغم من قيام الكلية التربوية بدرورها

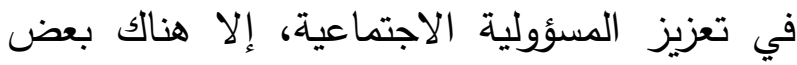

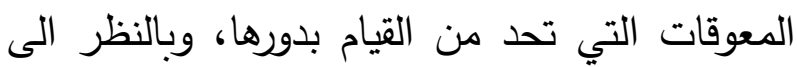
ترتيب أكثر المعوقات من وجه نظر عينة الدراسة،

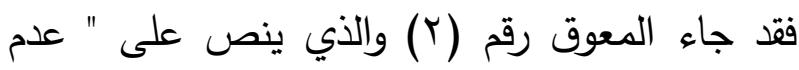
وجود قنوات ووسائل اتصال واضحة ومحددة بين الكلية والمجتمع الخارجي." بالمرتبة الاولى وبدرجة ولئ ولئ

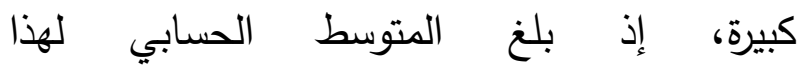

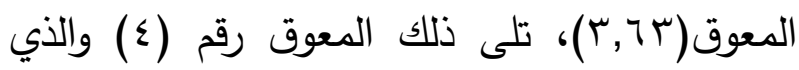
ينص على " ضعف الدافعية عند الطلاب في 


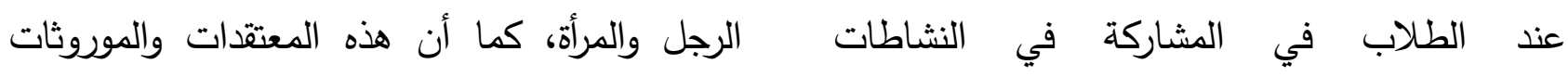

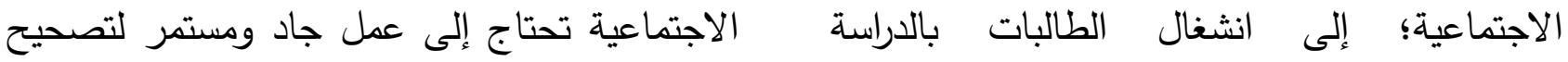
والتحضير للاختبارات التي تعوق مشاركتهم في المغلوط منها، والمحافظة على ما هو أصلي منها.

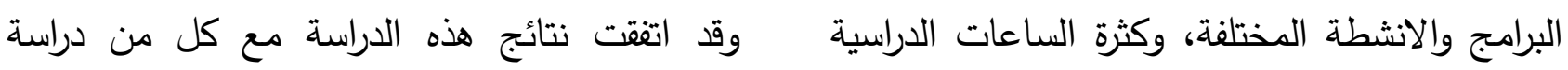

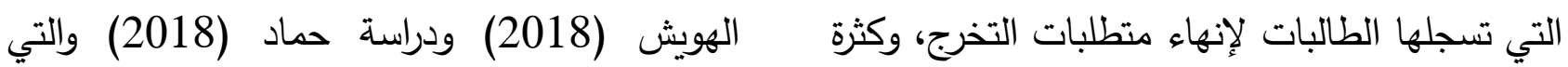
أشارت الى وجود معوقات تحد من دور كلية التربية في جامعة شقراء في تعزيز مسؤولية طلابها

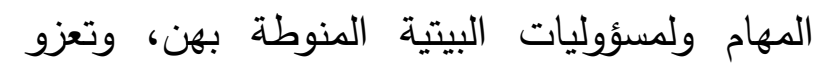
الباحثة النتيجة في عدم فهم معنى المسؤولية الاجتماعية، ودراسة حماد (2018) والتي أثارت فئل

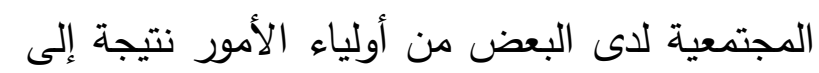
إلى وجود صعوبات تحد من دور كلية التربية في

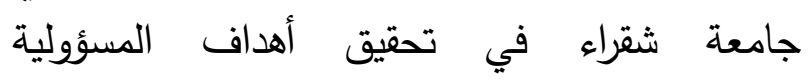
الاجتماعية عند الطلاب.

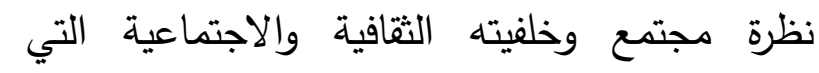
تتعكس آثارها سلبياً على المرأة مما يمنعها من والنائه ممارسة دورها في بناء المجتمع والمشاركة في عملية

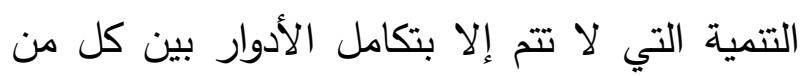
في تعزيز المسؤولية الاجتماعية عند طالبات كلية

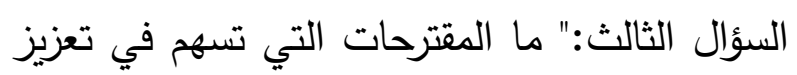

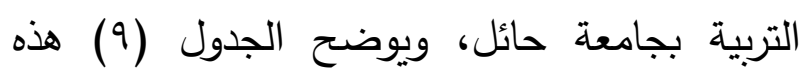
المسؤولية الاجتماعية عند طالبات كلية التربية

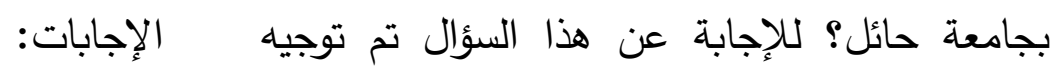

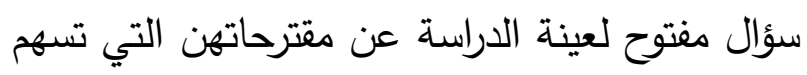
جدول (9): التكرارات والنسب المئوية والرتب لمقترحات العينة التي تسهح في تعزيز المسؤولية الاجتماعية عند طالبات كلية التربية بجامعة حائل مرتبة ترتيبا تنازلياً

\begin{tabular}{|c|c|c|}
\hline 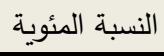 & 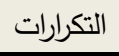 & 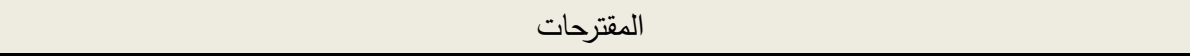 \\
\hline$\%$ \%, r. & Ir & 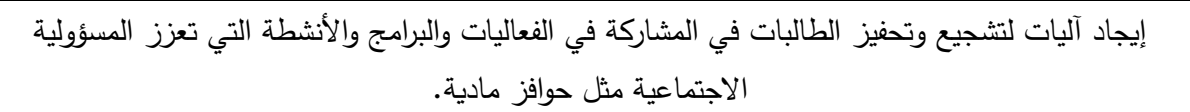 \\
\hline$\%$ \%, ฯ. & 110 & نالكتر ورفع مستوى الوعي الاجتماعي بتتمية المسؤولية الاجتماعية من خلال وحدات الاعلام بالكلية والموقع \\
\hline$\% \Gamma \leq, \varepsilon$. & 1.1 & دعم الأنشطة والمناهج التي تتمي الثعور بالمسئولية الاجتماعية لدى الطالبات. \\
\hline$\%$ \%r,o. & $1 \cdot r$ & تضمين المسؤولية الاجتماعية في المقررات والمناهج الدراسية والبرامج التي تقدمها الكلية التربية بجامعة حائل. \\
\hline$\% \curlyvee \wedge, q$. & 91 & تكثيف البرامج التدريبية في مجالات المسؤولية الاجتماعية. \\
\hline$\% r \cdot, r$. & 70 & تفعيل أدوار أعضاء هيئة التدريس في تعزيز المسؤولية الاجتماعية. \\
\hline
\end{tabular}

يتبين من الجدول رقم(8) أن أكثر المقترحات تكراراً الطالبات في المشاركة في الفعاليات والبرامج لاى عينة الدراسة (إيجاد آليات لتشجيع وتحفيز والأنشطة التي تعزز المسؤولية الاجتماعية مثل فئل 
الإداري والقيادي، مما يعزز مشاعر الولاء والانتماء للمؤسسة التعليمية. - احترام أنظمة الجامعة وقوانينها، والتي من شأنها

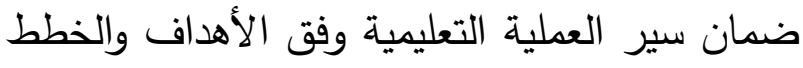

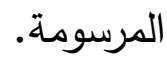
- تقديم الكلية العديد من البرامج والأنشطة والدورات والندوات التي من شأنها ترجمة المفاهيم العلمية إلى الى

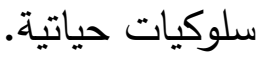

r- مجال تعزيز المسؤولية الاجتماعية تجاه

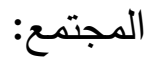
- توعية الطالبات بقيم وعادات وتقاليد المجتمع

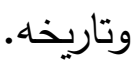
- التفاعل الإيجابي مع قضايا المجتمع ومشكلاته وتقديم الحلول الناجعة لها. r- مجال تعزيز المسؤولية الاجتماعية تجاه الوطن: - التأكيد على الوحدة الوطنية والتلاحم والتكافل بين أفراد المجتمع السعودي. - التصدي للمؤامرات التي تحاك على المملكة، عبر وسائل الإعلام المختلفة، ووسائل التواصل الاجتماعي.

- تعزيز الولاء والانتماء للوطن عن طريق ابراز نجاحات المملكة على مختلف الأصعدة. توصيات الدراسة: في ضوء نتائج الدراسة نوصي بما يلي: - إدراج مقرر التربية الوطنية والاجتماعية ضمن لهن لئية الخطة الدراسية لجميع طلاب الجامعة، باعتباره مادة
حوافز مادية.)، ويليها في المرتبة الثانية (نشر ورفع مستوى الوعي الاجتماعي بتنمية المسؤولية

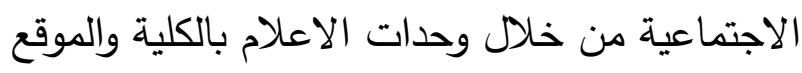

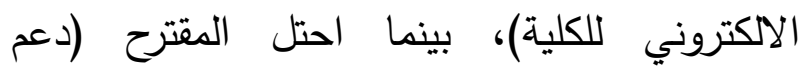
الأنشطة والمناهج التي تتمي الشعور بالمسئولية

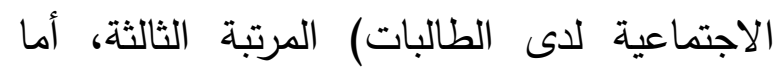
المقترح (تفعيل أدوار أعضاء هيئة التدريس في لإني تعزيز المسؤولية الاجتماعية) فقد جاء بالمرتبة الأخيرة. وتؤكد هذه النتيجة ضرورة توفير كل ما يلزم لتعزيز المسؤولية الاجتماعية عند الطالبات من خلال إيجاد آليات لتشجيع وتحفيز الطالبات في المشاركة في الفعاليات والبرامج والأنشطة، نشر ورفع مستوى لئن الوعي الاجتماعي بتتمية المسؤولية الاجتماعية باستخدام كافة الوسائل والامكانات المتاحة، وتضمين مفاهيم وأهداف المسؤولية الاجتماعية في الخطط والبرامج والمقررات الدراسية.

\section{الاستنتاجات}

من خلال النتائج يمكن تحديد دور كلية التربية بجامعة حائل في تعزيز المسؤولية الاجتماعية عند

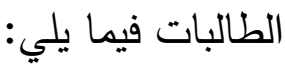
1- مجال تعزيز المسؤولية الاجتماعية تجاه

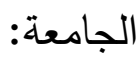
- - توفير البيئة التعليمية والمناخ الأكاديمي، والذي يسمح بالتفاعل الإيجابي بين الطالبات بعضهن

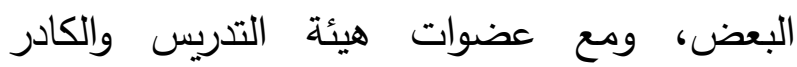




\section{مقترحات الدراسة}

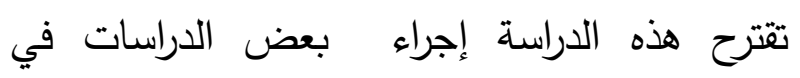
المجال، ومن ذلك ما يلي: - إجراء دراسات مماثلة لهذه الدراسة على المسؤولية الاجتماعية بالجامعات، وعلاقتها مع متغيرات أخرى التي تؤثر على حياتهج الأكاديمية والاجتماعية. المصادر والمراجع

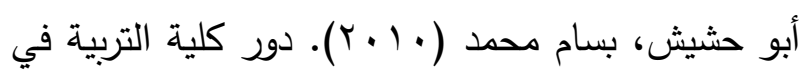
تتمية المواطنة لدى الطلبة المعلمين بمحافظات غزة دئ.

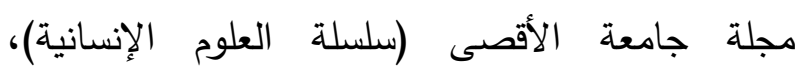
rVq - YO. ، (1) I \&

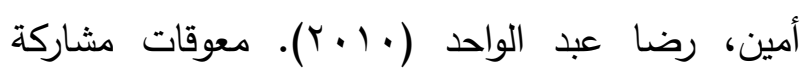

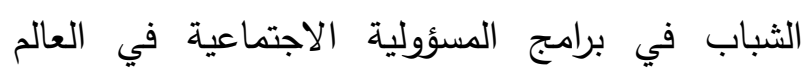

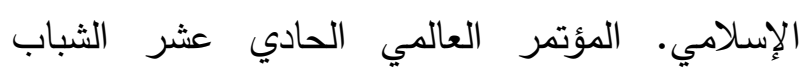

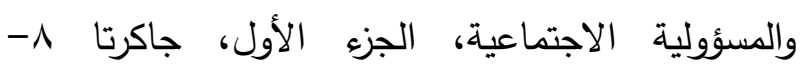

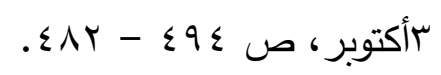

البنا، مايسة محمد (2008) دور كلية التربية الرياضية للبنات في الإسكندرية في تتمية المسؤولية الاجتماعية لاى الطلبات، المجلة العلمية للتربية البدنية والرياضية،

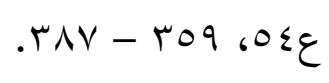
جابر ، محمود زكي، والمهدي، ناصر علي (2011). دور الجامعات في تعزيز المسؤولية الاجتماعية لدى ناصي طلبتها، دراسة ميدانية مقارنة بين جامعتي حلوان وجامعة لإنة الأزهر بفلسطين، جامعة القدس المفتوحة.

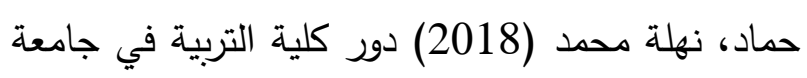

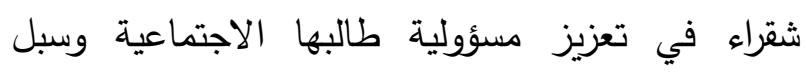
تفعيلها من وجهة نظر طلابها، مجلة الجامعة الإسلامية

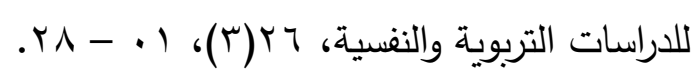

دراسية أساسية تواكب التطور خلال تعديل سلوك الطالب الجامعي. - عقد دورات في الأمن الفكري لطالبات الجامعة

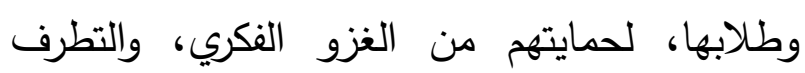
الديني، والمحافظة على هوية المجتمع. - تشجيع الطالبات على المشاركة في الأعمال التطوعية داخل الكلية وخارجها. - العمل على ايجاد البرامج التعليمية والإرشادية المناسبة التي تعمل على رفع مستوى المسؤولية الاجتماعية لاى الطالبات. - ضرورة تفعيل آليات التواصل بين الكلية مع التعاتل

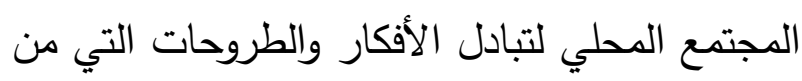
شأنها تعزيز المسؤولية الاجتماعية عند الطالبات. - عقد ندوات ومؤتمرات حول المسؤولية الاجتماعية في الجامعات السعودية وسبل تفعيلها في ضوك ورؤية رؤية $r \cdot r$. - فتح مراكز داخل الكلية لتفعيل التواصل ما بين الطالبات مع المجتمع المحلي. - إنشاء صفحة الكترونية تختص بمناقثة قضايا المجتمع بمشاركة الطالبات. - تكريم الطالبات اللواتي يتفاعلن مع قضايا لهيت المجتمع. - عمل حملات ومبادرات توعوية لنشر ثقافة ترشيد الاستهلاك الماء والكهرباء داخل الكلية. 
الاجتماعية لدى طالباتها في ضوء رؤية · م. ب، مؤتمر

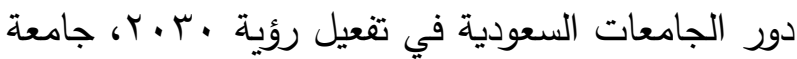

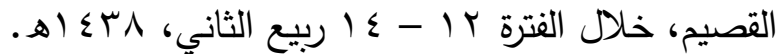
عوض، حسني، وحجازي، نظمية (2011) التي هدفت إلى التعرف على واقع المسؤولية الاجتماعية لدى طلبة جامعة القدس المفتوحة وتصور مقترح لبرنامج يرتكز إلى خدمة الجماعة لتنميتها، والتعرف على الصعوبات التي تحد دون تحقيقها، بحث مقدم إلى مؤتمر الخدمة الاجتماعية الأول، جامعة النجاح الوطنية. المجالي، سامي مشهور (11 (r). دور المؤسسة التربوية في ترسيخ مفاهيم المسؤولية المجتمعية. رسالة المعلم، وزارة التربية والتعليم - إدارة التخطيط والبحث

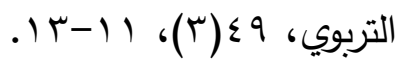

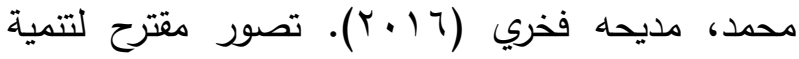
المسؤولية الاجتماعية للجامعات المصرية في ضوء مجتمع المعرفة. دراسات عربية في التربية وعلم النفس،

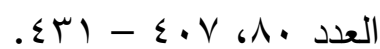

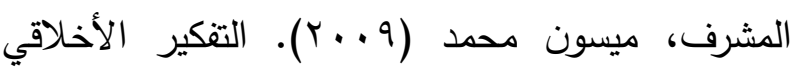
وعلافته بالمسؤولية الاجتماعية وبعض المتغيرات لدى طلبة الجامعة الإسلامية بغزة، رسالة ماجستير غير منشورة، الجامعة الإسلامية، غزة.

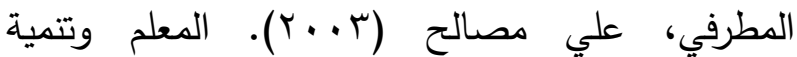
المسؤولية الاجتماعية لاى طلاب المرحلة الثانوية، رسالة دكتوراة، جامعة أم القرى، المملكة العربية

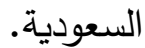
المومني، حازم عيسى (11 • ب). المسؤولية الاجتماعية لدى طلبة كلية الحصن الجامعية وعلاقتها بدافعية
الرشيدي، حسين مجبل هدبا(2017) دور كلية التربية الأساسية في تتمية المسؤولية الاجتماعية والوعي بها لاى طلابها، جمعية الثقافة من أجل التمية،

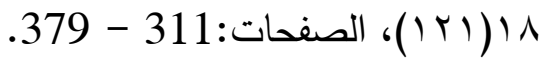
الرويشد، فهد عبدالرحمن (2007) الحرية دور جامعة و المسؤولية الاجتماعية لدى طلاب كلية التربية الأساسية بدولة الكويت، مجلة العلوم التربوية، جامعة القاهرة،

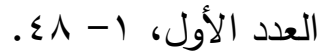

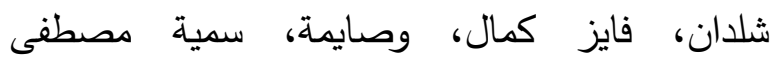

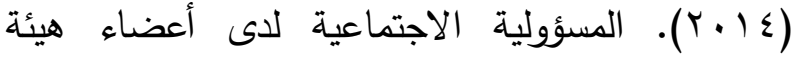
التدريس في الجامعة الاسلامية وسبل تقعيلها. المجلة

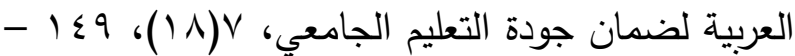
$.1 \vee 9$

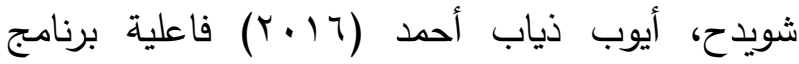
معرفي سلوكي في تتمية المسؤولية الاجتماعية لدى الأيتام بمعهد الأمل بغزة. رسالة ماجستير غير منشورة، كلية التربية، الجامعة الإسلامية بغزة، فلسطين.

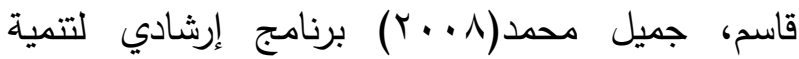
المسؤولية الاجتماعية لدى طلاب المرحلة الثانوية. رسالة ماجستير غير منشورة، كلية التربية، الجامعة الإسلامية بغزة. العبيد، إبراهيم بن عبدالله (T 1 ץ) تصور مقترح لتفعيل دور الجامعات السعودية في تنمية المسؤولية الاجتماعية لاى طلابها. مجلة كلية التربية، جامعة أسيوط - كلية التربية، بr(ع)، الصفحات :485 - 551 . عرفات، نجاح السعدي، والعمودي، هالة سعيد (2017). دور جامعة أم القرى في تعزيز المسؤولية 
الوادعي، مسفر أحمد (2018). دور معلم العلوم

الإنجاز، إربد للبحوث والدراسات - العلوم التربوية، 15

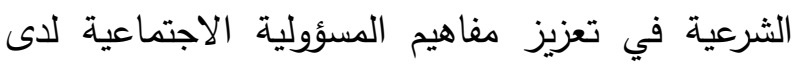
236 - $19 \wedge$ (2) طلاب المرحلة الثانوية من وجهة نظر مشرفي العلوم الثرعية بنطقة عسير، المجلة الدولية التربوية

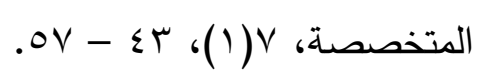
النويهي، آية عبدالله (ع ا • ب). دور الجامعات في تقدم البحث العلمي وأثره على المجتمع، المجلة العربية لضمان جودة التعليم، العدد السابع.

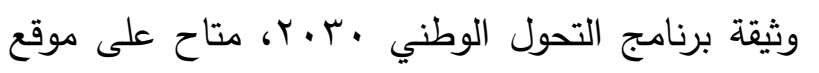
الهويش، يوسف محمد (2018) التي هدفت إلى دور

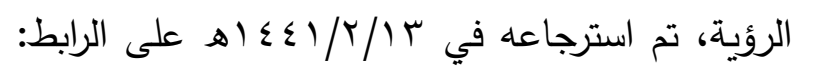
كلية التربية في جامعة شقراء في تعزيز مسؤولية طالبها

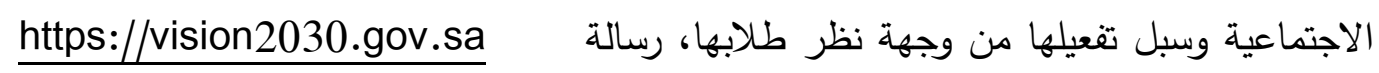

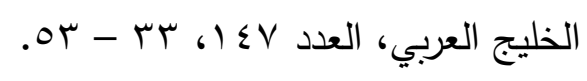




\title{
The Role of The Faculty of Education at the University of Hail in Promoting Social Responsibility Among Students in the Light of the Vision 2030 for Saudi Arabia
}

\author{
Dr. Haifa Ali Taifoor, \\ Assistant Professor of Educational Administration \\ Department of Kindergarten, College of Education, \\ University of Hail
}

\begin{abstract}
University of Hail in promoting social responsibility among students in the light of the Vision 2030 for Saudi Arabia, by determining the level of social responsibility among students, and to identify the difference in the level of social responsibility according to the impact of study variables, and identify the most important obstacles to In order to achieve the objectives of the study, the researcher used the descriptive analytical method. A questionnaire was designed to collect data. The study was applied to a sample of (314) students. The study found that the level of social responsibility among the students of the faculty of education at the University of Hail came largely at the level of the total tool and in all fields, and also revealed the presence of statistically significant differences in the level of social responsibility due to the variable of the school year, and the absence of significant differences Statistically attributed to the estimation variable، The results also revealed that the most important obstacles to the promotion of social responsibility among students is the lack of clear and specific channels and means of communication between the college and the external community, and that the most proposals that contribute to the promotion of social responsibility, find mechanisms to encourage and motivate students to participate in events, programs and activities that promote social responsibility, and recommended Study the need to work to find appropriate educational and extension programs that work to raise the level of social responsibility among students

Keywords: Social Responsibility, Faculty of Education, University of Hail, Vision 2030.
\end{abstract}

